\title{
Knowledge and Presuppositions*
}

\author{
Michael Blome-Tillmann \\ draft, forthcoming in Mind
}

\begin{abstract}
The paper explicates a new way to model the context-sensitivity of 'knows', viz. a way that suggests a close connection between the content of 'knows' in a context $C$ and what is pragmatically presupposed in $C$. After explicating my new approach in the first half of the paper and arguing that it is explanatorily superior to standard accounts of epistemic contextualism, the paper points, in its second half, to some interesting new features of the emerging account, such as its compatibility with the intuitions of Moorean dogmatists. Finally, the paper shows that the account defended is not subject to the most prominent and familiar philosophical objections to epistemic contextualism discussed in the recent literature.
\end{abstract}

\section{Introduction}

In recent work on Epistemic Contextualism (EC), considerable suspicion has arisen as to whether EC really has the philosophically interesting consequences that its advocates have traditionally claimed it to have. Ernest Sosa, for instance, has argued that, as a linguistic or semantic view, viz. as the view that the predicate 'know' is indexical and may thus change its content with context, EC is "largely irrelevant to epistemological concerns." Independently of Sosa, other distinguished philosophers have raised doubts as to whether contextualists can meet the epistemological cheques they are so eager to issue: Timothy Williamson and Crispin Wright, for instance, have argued that if EC were correct, then its advocates would be unable to felicitously assert, and thus defend, the view that we ever satisfy the predicate 'know'. ${ }^{2}$ Along similar lines, Robert Fogelin has objected to EC on the grounds that it entails what David Lewis calls 'elusiveness', i.e. the view that

\footnotetext{
*For extensive discussion of the ideas in this paper I am very grateful to Brian Ball, Steward Cohen, Dorothy Edgington, Ralph Wedgwood, Crispin Wright and to five anonymous referees of this journal. Special thanks are due to Tim Williamson, who supervised the DPhil thesis this paper emerged from.

${ }^{1}$ See Kornblith 2000, p. 24, Lehrer 2000, and Sosa 2000, 2005.

${ }^{2}$ See Williamson 2001 and Wright 2005.
} 
one ceases to satisfy 'know' as soon as one begins to engage in epistemology. ${ }^{3}$ According to Fogelin, it is due to this elusiveness that contextualism amounts to nothing less than pyrrhonism, the ghastly view that "philosophical attempts to defend knowledge inevitably wind up undercutting it."4

EC is thus under rather heavy philosophical fire and the above objections have convinced many theorists that the view cannot offer what it promises: namely, a resolution of the sceptical puzzle. To a large extent, I agree with this widely held criticism. The accounts of EC that are currently defended in the literature are in fact either subject to the objections I have alluded to or they are unsatisfactory for yet further reasons, relating to a number of independent methodological problems and counterexamples. ${ }^{5}$ However, in spite of my pessimistic attitude towards those accounts of EC that are currently discussed in the literature, I also believe that the general idea of a philosophically interesting contextualist semantics of 'know' can be coherently developed and safeguarded against the attacks from Fogelin, Sosa, Williamson and Wright. To my mind, the difficulties of the established versions of EC are characteristic of precisely those established versions, while the general idea of the context-sensitivity of 'know' leaves enough room for interesting philosophical manoeuvring. In this paper I attempt such manoeuvring and aim to develop a novel contextualist approach to the semantics of 'know'. 6

The paper is structured as follows. To begin with, Section 1 gives a brief sketch of the contextualist account that I consider most promising: David Lewis's. After introducing Lewis's view, I consider a familiar objection to it and propose, in response, to replace Lewis's Rule of Attention with what I call the Rule of Presupposition. To substantiate this approach, Section 2 looks in more detail at Stalnaker's work on the notion of a pragmatic presupposition, while Section 3 summarises the emerging view and gives replies to objections. Sections 4-8 are then devoted to an in-depth discussion of sceptical puzzles: I argue that my new Lewisian approach to the semantics of 'know' - I call it Presuppositional Epistemic Contextualism (PEC) - is explanatorily superior to Lewis's original approach, not only because it accounts more adequately for actual speakers' intuitions about sceptical arguments, but also, and crucially, because it has the resources to integrate G.E. Moore's views on scepticism within a contextualist framework: epistemic

\footnotetext{
${ }^{3}$ See Fogelin 2000, Villanueva 2000, and, for related views, Feldman 1999 and Pritchard 2002.

${ }^{4}$ Fogelin 2000, p. 44.

${ }^{5}$ See fn. 8 , p. 3 for an outline of recent versions of EC and their problems.

${ }^{6}$ Further objections that have led many theorists to reject EC are of a more linguistic nature and call into question EC's error-theory or address syntactic issues relating to the contextualist's analogy between 'know' and gradable adjectives such as 'flat', 'tall' or 'empty'. For responses to objections of this type see and Neta 2003b, Ludlow 2005, DeRose 2006, Blome-Tillmann 2008. I address issues relating to EC's error-theory and the semantic blindness objection in Section 7 of this paper.
} 
contextualism and Moorean dogmatism no longer have to be conceived of as rival accounts of the same data.

The remainder of the paper, i.e. Sections 9-13, then discusses the relation of PEC to the aforementioned objections to EC. While Section 9 is devoted specifically to objections to PEC, I argue, in Section 10, that 'knowledge' is - pace Lewis - non-elusive and I use this result to defend PEC against Fogelin's charge that contextualism collapses into pyrrhonism. Section 11 is then devoted to Sosa's objection that EC is philosophically irrelevant, which I dismiss on the grounds that, contrary to Lewis's EC, PEC does not entail that contexts of epistemological enquiry are inevitably sceptical. Subsequently, I argue along similar lines, in Section 12, that PEC avoids Williamson's and Wright's objection: the defender of PEC is in a position to felicitously assert, and thus defend, the view that we often satisfy the predicate 'know'. Finally, Section 13 summarises the discussion, reviews the advantages of PEC over Lewis's original version of EC and concludes that epistemic contextualism, when rightly construed, has interesting and substantial philosophical entailments.

Obviously, the paper has a strong focus on David Lewis's work, and it might be objected that such focus is unwarranted. After all, a multitude of different accounts of EC have been proposed in recent years. Besides Lewis's account there are, for instance, Stewart Cohen's internalist version of EC, Keith DeRose's and Mark Heller's contextualised safety accounts of 'knowledge', Steven Rieber's account, which analyses 'know' in terms of 'explains', Ram Neta's account, on which the satisfaction of 'know' is modelled in terms of 'evidence', which Neta then takes to be context-sensitive, and, finally, Jonathan Schaffer's contrastivism, which is, if not a version of EC, at least in many respects similar to the view. ${ }^{7}$ These accounts are important and have received much attention in the recent literature. Moreover, most of these accounts are not - or at least do not seem to be - subject to the same objections as Lewis's account is. So why do I turn back to Lewis's approach and address the relevant objections again? Why propose a novel Lewisian approach to EC?

As I have indicated above, although Lewis's version of EC is presumably the most widely criticised account of EC in the literature, I nevertheless believe it to be the most promising one. Thus, the answer to the question why we ought to give Lewis's views a second chance is that each of the other accounts in the literature has its own downsides and weaknesses; downsides and weaknesses that my novel Lewisian account of EC does not share. Unfortunately, an exhaustive discussion of each of the aforementioned accounts is beyond the scope of this paper. However, a brief glance at the recent (and forthcoming) literature will confirm my contention that, from a contextualist point of view, a fresh approach to EC is desirable. ${ }^{8}$ The goal of this paper

\footnotetext{
${ }^{7}$ See fn. 8 below for references to the relevant literature.

${ }^{8}$ Here is a brief outline of the mentioned accounts and their weaknesses. Keith DeRose's
} 
is to develop such a fresh approach to the context-sensitivity of 'know'.

\section{Knowledge}

What is EC? First and foremost, EC is a semantic view, viz. the view that 'knowledge'-ascriptions can change their contents with the conversational context. To be more precise, EC is the view that the predicate 'know' has an unstable Kaplan character, i.e. a character that does not map all contexts on the same content. According to EC, 'know' is an indexical expression. Notwithstanding this purely linguistic characterisation of EC, contextualists have traditionally argued that their views have considerable philosophical impact, this being due to the alleged fact that their linguistic views about 'know' provide the resources for a resolution of sceptical puzzles. Thus, even though contextualists typically tend to argue that EC is sufficiently motivated by the linguistic data deriving from familiar examples such as DeRose's Bank Case or Cohen's Airport Case, ${ }^{9}$ they have also frequently argued that their linguistic views about 'know' are of considerable epistemological sig-

$(1995,2004,2006)$ contextualised safety approach to EC is, as I argue elsewhere (BlomeTillmann forthcoming), subject to numerous counterexamples. DeRose's notion of what is epistemically relevant in $C$ cannot be explicated in terms of similarity spheres that are centred on actuality. Mark Heller $(1989,1999)$ defends a similar approach to EC that is subject to the same objections. Stewart Cohen's (1999) internalist version of EC has also been criticised extensively in the literature (see, for instance, Pritchard 2002 and Stanley 2005). Steven Rieber (1998), who offers a version of EC that analyses 'know' in terms of 'explains', has been decisively criticised by Neta (2002, pp. 667-8). Moreover, Rieber's account employs the notion of a "salient possibility" or a "salient [...] contrast" (Rieber 1998, p. 169), which is defined by means of a rule that is very similar to Lewis's problematic Rule of Attention (see Williams 2000 and Section 1 of this paper). Jonathan Schaffer $(2004 a, 2005,2007)$ proposes a contrastivist account of knowledge that is not only troubled by scepticism and closure failure (see Kvanvig 2007 for arguments) but also relies on a linguistically questionable analogy between 'know' and 'prefer' (see Stalnaker 2004). For further criticism of Schaffer's approach see Neta forthcoming. Finally, Ram Neta $(2002,2003 \mathrm{a}, 2003 \mathrm{~b})$ proposes a version of EC that takes 'evidence' to be contextsensitive and 'know' to be analysable in terms of 'evidence'. Neta's approach thus treats the notion of evidence as explanatorily more basic than the notion of knowledge, a view that many theorists may find unattractive nowadays (see, for instance, and Williamson 2000, Hawthorne 2004, Stanley 2005). A more serious shortcoming of Neta's account, however, is its incompleteness: Neta defines the possession of evidence for $p$ in $C$ in terms of one's evidence in $C$ favouring $p$ over all alternatives to $p$ that are relevant in $C$ (Neta 2002 , p. 673 , Neta 2003 a, p. 21 ), but we are not told what it means for an alternative to be relevant in $C$. This is problematic, however, for, as Schaffer and Sosa remark with regard to relevant alternatives accounts of EC, "[p]ending a precise account of relevance, contextualism will remain unacceptably occult" (Schaffer 2004a, p. 88, quoting Sosa 1986, p. 585) and the "mechanism of relevance remains as mysterious as magic" (Schaffer 2004a, p. 88). One of the goals of this paper is to develop a comprehensive account of the notion of a relevant alternative.

${ }^{9}$ See Cohen 1999, p. 58 and DeRose 1992, p. 913. 
nificance. ${ }^{10}$ David Lewis's conceives of his version of EC as providing us with a response to the sceptical problem, and it is this type of EC that I am interested in in this paper. Let us thus take a closer look at David Lewis's views on scepticism and contextualism.

According to Lewis:

(L) $x$ satisfies 'knows $p$ ' in context $C \leftrightarrow x$ 's evidence eliminates every $\neg p$ world, except for those that are properly ignored in $C .{ }^{11}$

In addition to this definition of the satisfaction of 'know', Lewis stipulates a set of "rules of relevance" specifying which possibilities can be properly ignored in a given context. It is this set of rules that is meant to determine how the content of 'know' is influenced by particular contextual factors. The rule doing the main explanatory work with regard to sceptical puzzles is Lewis's "Rule of Attention" (RA):

(RA) If $w$ is attended to by the speakers in $C$, then $w$ is not properly ignored in $C$.

As Lewis points out, (RA) eventually boils down to the apparent triviality that "a possibility not ignored at all is ipso facto not properly ignored." 12

How are (RA) and (L) intended to resolve sceptical puzzles? Firstly, note that when confronted with sceptical arguments, one inevitably attends to sceptical possibilities, for sceptical hypotheses, i.e. sentences expressing sceptical possibilities, form an integral part of sceptical arguments. Thus, it follows from (RA) that any context in which one considers sceptical arguments is a context in which one does not properly ignore sceptical possibilities. Secondly, conceding that sceptical possibilities resist elimination by one's evidence, it follows from (RA) and (L) that, for all propositions $p$ about the external world, one does not satisfy 'knows $p$ ' in contexts in which one considers sceptical arguments. ${ }^{13}$ Such contexts are, as I shall put it henceforth, sceptical contexts. Thirdly, note that even though Lewis's account entails that we do not satisfy 'knows $p$ ' in contexts in which sceptical

\footnotetext{
${ }^{10}$ The only contextualist who does not aim to resolve sceptical puzzles is Ludlow (2005), who defends EC purely on the basis of linguistic data. Note also that there could be versions of EC that can account for the data relating to the Bank Case and the Airport Case but that cannot account for our sceptical intuitions. On such an account, the epistemic standards never rise as high as they need to to make the sceptic's assertion of 'Nobody knows that they have hands' come out as true.

${ }^{11}$ On Lewis's approach, our evidence consists in the totality of our perceptual experiences and memory states and a possibility $w$ is eliminated by an experience (or memory state) iff the experience's (or the memory state's) existence (rather than its content) conflicts with $w$. Lewis 1996, p. 224.

${ }^{12}$ Lewis 1996, p. 230.

${ }^{13}$ Note that sceptical possibilities resist elimination by one's evidence only if the contents of experiences and memories are individuated internalistically. In this paper I shall grant the sceptic such an internalist conception of evidence.
} 
arguments are at issue, it also entails that we often do so in quotidian contexts: in quotidian contexts we do not attend to sceptical possibilities, can therefore properly ignore sceptical possibilities and thus often satisfy 'knows $p^{\prime}$ for various propositions $p$ about the external world. ${ }^{14}$

Lewis's views can thus be seen as accounting for both our Anti-Sceptical Intuitions (ASI) and our Sceptical Intuitions (SI), which are to be represented as follows:

(ASI) People often speak truly when they assert 'I know p.'

(SI) People sometimes speak truly when they assert 'Nobody knows $p$ ' in contexts in which sceptical arguments are discussed.

However, if the semantic value of 'know' can change in a way allowing for both (ASI) and (SI) to be true, why then are we puzzled by sceptical arguments? Lewis replies that the puzzle arises because we are often unaware of the relevant contextual shifts in the content of 'know'. We simply do not always realise that our everyday 'knowledge'-ascriptions express propositions that are perfectly compatible with the propositions expressed by 'knowledge'negations in sceptical contexts. ${ }^{15}$

Now, an obvious problem for Lewis's (RA) is that it makes it too difficult to satisfy 'know'. As Michael Williams puts it:

[T] he Rule of Attention makes retaining knowledge too hard. Conceding for the present that far-fetched sceptical possibilitiesbrains-in-vats, demon-deceivers - resist elimination by evidence, the Rule ensures that a person's knowledge vanishes every time such a possibility enters his head. ${ }^{16}$

As it stands, (RA) allows the mere attendance to sceptical hypotheses in a context $C$ to make it impossible to properly ignore such counter-possibilities in $C .{ }^{17}$ As Williams points out, however, this is too strong a view. Imagine you saw your teenage son sneaking away through the window of his room late at night. When you confront him the next morning he replies somewhat desperately: 'How do you know I left the house? I mean, for all you know you might have dreamt it. It was late at night, wasn't it?' On Lewis's account you find yourself in a context in which you have to admit to your son that you do not 'know' that he sneaked away at night, and this surely

\footnotetext{
${ }^{14} \mathrm{I}$ assume that none of the other Lewisian rules of relevance such as the Rule of Actuality, Resemblance or Belief marks out sceptical worlds as relevant in quotidian contexts.

${ }^{15}$ This strategy, relying on what I have elsewhere called the phenomenon of 'semantic blindness', has been criticized widely, but see Blome-Tillmann 2008 for a comprehensive defence.

${ }^{16}$ Williams 2001, p. 15.

${ }^{17}$ This is particularly absurd in cases in which a participant to a conversation attends to a sceptical possibility in their own thought only, i.e. without mentioning the possibility to other speakers.
} 
is not just a pity, it is rather also mistaken: of course you 'know' that your son sneaked away through the window of his room last night - you saw him doing so, after all.

Lewis's (RA) is thus too strong. However, an alternative that puts you in a more authoritative position regarding your son is easily obtained. Note that by means of (RA) Lewis exploits the contrast between ignoring a proposition and attending to it. Lewis: "if in this context we are not in fact ignoring it but attending to it, then for us now it is a relevant alternative." 18 However, it seems obvious that, pace Lewis, merely attending to - or directing one's mind towards - some possibility $w$ in $C$ is not enough for making it impossible to properly ignore $w$ in $C$ in the epistemologically relevant sense. The notion of ignoring I have in mind is thus not that of ignoring $w$ as opposed to attending to $w$, but rather that of ignoring $w$ as opposed to taking $w$ seriously. On this second reading you surely can attend to the possibility that you merely dreamt that your son sneaked out of his window last night while nevertheless ignoring this possibility in a straightforwardly practical sense: you can surely entertain the thought that you merely dreamt, or direct your mind towards that possibility, without taking this very possibility seriously or giving it any credence. $^{19}$

The idea of replacing Lewis's (RA) with a rule employing the notion of taking a possibility seriously instead of merely attending to it comes to mind: if a possibility is taken seriously in a context $C$, i.e. if it is among the 'live options' in $C$, then it cannot be properly ignored in $C$. However, what exactly does it mean for a possibility to be a 'live option' in a context $C$ ? One way to explicate the notion at issue is by means of the notion of a pragmatic presupposition: a possibility $w$ is taken seriously in $C$ just in case $w$ is compatible with the speakers' pragmatic presuppositions in $C$. On this view, we can implement the idea that 'live options' cannot be properly ignored by means of the following Rule of Presupposition:

(RP) If $w$ is compatible with the speakers' pragmatic presuppositions in $C$,

\footnotetext{
${ }^{18}$ Lewis 1996, p. 230; Lewis's emphasis.

${ }^{19}$ Lewis himself canvasses a normative variant of his position, which, he acknowledges, conflicts with (RA) - namely by modifying (L) so that it ends "except for those possibilities which we could properly have ignored [if we hadn't attended to them]" (Lewis 1996, p. 232). However, this normative approach effectively eliminates (RA) and thus the contextualist element from Lewis's approach: Lewis's normative approach is to be paired with criteria distinguishing those possibilities that one can properly ignore (or could have properly ignored) in a context from those that one cannot properly ignore (or could not have properly ignored) in a context. In what follows I offer such criteria.
} 
then $w$ cannot be properly ignored in $C .{ }^{20},{ }^{21}$

Now, why would we want to link the content of 'know' in $C$ to the speakers' presuppositions in $C$ rather than to other contextual features? The advantages of such a move are fairly obvious: since speakers can, to a certain extent, voluntarily decide what they take seriously and which propositions they presuppose, they have, to a certain extent, voluntary control over the content of 'know' in their contexts. For instance, as long as you make clear to your son that the possibility that you dreamt seeing him sneaking out of his window is not a 'live option' in your conversation, you remain in a context in which you satisfy 'know', even though your son has drawn attention to the

\footnotetext{
${ }^{20}$ Note that my account does not coincide with Lewis's when he rephrases his account in terms of 'proper presuppositions'. Here is Lewis: "Say that we presuppose proposition $p$ iff we ignore all possibilities in which $\neg p$. To close the circle: we ignore just those possibilities that falsify our presuppositions. Proper presupposition corresponds, of course, to proper ignoring. Then $x$ knows that $p$ iff $x$ 's evidence eliminates every possibility in which $\neg p$ - Psst! - except for those possibilities that conflict with our proper presuppositions." Lewis 1996, p. 225; Lewis's emphasis; symbolism adjusted. In this passage, Lewis stipulatively defines the notion of proper presupposing in terms of the notion of proper ignoring, which is then defined in terms of Lewis's rules of proper ignoring - including the Rule of Attention. In the framework of PEC, however, the notion of proper ignoring is defined in terms of the Rule of Presupposition and Lewis's remaining rules. Surely, once the notion of proper ignoring is thus defined we could, just like Lewis does, introduce a notion of proper presupposing, one on which what is properly ignored is incompatible with what we properly presuppose. But that notion would be distinct from the notion of a pragmatic presupposition, even though it would be partially defined in terms of it (viz. in terms of $(\mathrm{RP})$ ). Thus, the relation between proper ignoring and pragmatic presupposing is a very different one on my account than the relation between proper ignoring and proper presupposing on Lewis's.

${ }^{21}$ Jonathan Schaffer $(2004 a, 2005,2007)$ agrees that Stalnaker's notion of a pragmatic presupposition should play a role in the semantics of 'know' when claiming that, within the framework of his contrastivist account, the contrasts relevant in $C$ are "always recoverable" from Stalnaker's context set or that the context set "provides the default source of contrasts" (Schaffer 2005, p. 249). However, Schaffer seems sceptical about the contextualist approach defended here when describing Lewis's rules as "little more than a laundry list of rules of thumb, replete with unclear principles, subject to a variety of counterexamples, and open to skeptical usurpation as merely pragmatical" (Schaffer 2004a, p. 88, but see also Schaffer 2005, p. 267). More importantly, Schaffer explicitly rejects the idea of explicating Lewis's notion of proper ignoring in terms of what is pragmatically presupposed. Schaffer: "if the contextualist deploys anything like Stalnaker's notion of a context set, then [she] must forgo such Lewisian Rules as Actuality, Belief, and Resemblance, since the context set need not contain actuality, need not correspond to anyone's beliefs, and is not closed under resemblance [...]. As such, contextualism would no longer underwrite, e.g. Lewis's solutions to skepticism, Gettier cases, and the lottery paradox, since these require Actuality, Belief, and Resemblance." (Schaffer 2004a, pp. 99, fn. 27). Considering my above formulation of (RP), however, it is fairly obvious that, pace Schaffer, the contextualist can deploy Stalnaker's notion of a context set in explicating the notion of proper ignoring. For further discussion of the interaction between (RP) and the remaining Lewisian rules see Section 3 of this paper. For discussion of Schaffer's contrastivist account see and Stalnaker 2004, Kvanvig 2007, Neta forthcoming.
} 
possibility that you might have dreamt the relevant episode. ${ }^{22}$ Similarly, as long as the speakers in a context $C$ pragmatically presuppose the negations of sceptical hypotheses, the epistemic standards relevant for the evaluation of 'know' in $C$ remain the standards of quotidian contexts, even though attention may have been drawn to sceptical possibilities: sceptical possibilities can still be properly ignored. ${ }^{23}$ Thus, replacing Lewis's Rule of Attention by my Rule of Presupposition avoids the above-mentioned problems pointed to by Williams. ${ }^{24}$

\section{Presuppositions}

Under what conditions does a speaker presuppose a given proposition $p$ ? Of course, we have a pre-theoretical understanding of what it means to presuppose something: one presupposes $p$ when one takes $p$ for granted or when one assumes $p$, possibly only for the purposes of the conversation one is participating in. However, even though we have an intuitive grasp of what a presupposition is, our pre-theoretical concept is, presumably, too vague to play centre stage in a contextualist approach to the semantics of 'know'. In this section I will therefore look for an explication or sharpening of our intuitive concept that can then be shown to figure in an explanation of mostly familiar data about 'knowledge'-ascriptions and sceptical puzzles.

When discussing the notion of a presupposition in a philosophical or linguistic context Robert Stalnaker's work on the topic comes to mind immediately. A first suggestion might thus be to adopt his rather well developed notion of a pragmatic presupposition for the present purposes. And in factas will become obvious later-Stalnaker's notion is ideally suited to putting flesh on the skeleton of a presupposition-based EC as outlined above. Thus, if I am right, the very notion that has application in Stalnaker's accounts of linguistic phenomena as diverse as assertion, sentence presupposition, indicative conditionals, and others also plays a crucial role in the semantics of 'knowledge'-ascriptions.

What, then, is a Stalnakerian pragmatic presupposition? Before answer-

\footnotetext{
${ }^{22}$ What happens if your son refuses to pragmatically presuppose that you did not dream? In such a case you will find yourself in what Stalnaker (1978) calls a defective context. As I argue below, in defective contexts it is unclear whether you satisfy 'knows', this view providing an attractive explanation of our unclear intuitions about the acceptability of 'knowledge'-ascriptions in defective contexts (see Section 7, pp. 27ff.).

${ }^{23}$ I again assume that none of the other Lewisian rules that (RP) is to be supplemented with prohibits properly ignoring $s h$-worlds in $C$.

${ }^{24}$ The importance of the idea that the conversational participants should have authority over the 'epistemic standards' of their own context has been emphasised by many contextualists in recent years. See especially DeRose 2004, but also Cohen 1999, Neta 2002, and Schaffer 2005. As we shall see in greater detail below, authority over one's own epistemic standards can be made available by pairing (RP) with a suitable notion of pragmatic presupposition.
} 
ing this question it is imperative to note that Stalnaker thinks of the notion at issue as primitive: pragmatic presuppositions are, according to Stalnaker, propositional attitudes sui generis and as such insusceptible to analysis or definition. However, even though Stalnaker intends the notion to remain ultimately undefined, he offers, throughout his work, several explications of the notion that are meant to approximate the concept and give the reader a closer grasp of the notion. Stalnaker justifies this approach as follows:

It may be charged that [the concept of a pragmatic presupposition is] too unclear to be the basic [concept] of theory, but I think that this objection mistakes the role of basic concepts. It is not assumed that these notions are clear. In fact, one of the points of the theory is to clarify them. So long as certain concepts all have some intuitive content, then we can help to explicate them all by relating them to each other. The success of the theory should depend not on whether the concepts can be defined, but on whether or not it provides the machinery to define linguistic acts that seem interesting and to make conceptual distinctions that seem important. With philosophical as well as scientific theories, one may explain one's theoretical concepts, not by defining them, but by using them to account for the phenomena. ${ }^{25}$

Bearing in mind this caveat, let us consider Stalnaker's most recent explication of the notion.

In his latest work on the topic Stalnaker proposes a two-stage explication of the notion of a pragmatic presupposition: firstly, he defines what he calls common ground in terms of the notions of belief and acceptance, and then, in the second step, he explicates the notion of a pragmatic presupposition in terms of the notions of belief and common ground. ${ }^{26}$ Here is Stalnaker's definition of the concept of common ground:

(CG) It is common ground that $p$ in a group $G \leftrightarrow$ all members of $G$ accept (for the purpose of the conversation) that $p$, and all believe that all accept that $p$, and all believe that all believe that all accept that $p$, etc. ${ }^{27}$

\footnotetext{
${ }^{25}$ Stalnaker 1970, p. 46. See also Stalnaker 1974, p. 50.

${ }^{26}$ Strictly speaking, Stalnaker gives a three-stage definition of the notion of pragmatic presupposition, the first step consisting of a definition of 'acceptance'. These details do not concern me in this paper, however. I work instead with an intuitive notion of acceptance for the purpose of one's conversation. See Stalnaker 2002, p. 716 and Stalnaker 1984, pp. 79-82 for the notion of acceptance.

${ }^{27}$ Stalnaker 2002 , p. 716 uses a simple conditional rather than a biconditional but considering that he aims to "define" common ground a biconditional appears more adequate here. Moreover, note that the relevant beliefs are implicit beliefs (see Lycan 1986 for a discussion of implicit beliefs).
} 
Having thus defined the notion of common ground, Stalnaker gives the following definition of a pragmatic presupposition:

(PP) $x$ pragmatically presupposes $p \leftrightarrow x$ believes $p$ to be common ground. ${ }^{28}$

Thus, according to Stalnaker's explication a speaker pragmatically presupposes $p$ iff she believes that all members participating in her discourse accept $p$, believe that all accept $p$, believe that all believe that all accept $p$, etc. Pragmatic presuppositions are, accordingly, a special type of belief and as such a special type of propositional attitude.

I have claimed above that one advantage of $(\mathrm{RP})$ over $(\mathrm{RA})$ is that the participants in a conversation can decide to presuppose a proposition and thus have, to some extent, voluntary control over what 'know' expresses in their context. Stalnaker's notion of a pragmatic presupposition as just explicated, however, does not allow for voluntary presupposing: since belief is spontaneous and thus not under one's direct voluntary control, one can hardly choose to believe that a proposition $p$ is common ground. On the basis of (PP), presupposing is outside the realm of the voluntary. Is this a problem for my account?

Note that there are a few problems with (PP) arising from its not allowing for voluntary presupposition. In fact, Stalnaker himself, in a footnote, considers the following case relating to the issue:

\section{Foreign Language:}

There may in some cases be a divergence between [pragmatic] presupposition and belief [...]. A speaker may presume that something is common ground, even when he is only hoping that it will become common ground. Suppose I am in a country whose language I do not speak. I have no reason to think that the person I approach on the street speaks English, but I am desperate, so I try: "Is there a public toilet nearby?" If I am lucky, it will become common [ground] that we both speak English. ${ }^{29}$

On Stalnaker's view, the speaker in Foreign Language pragmatically presupposes the proposition that the addressee speaks - or at least understandssome English, even though he does not believe that proposition to be part of the common ground. Such an interpretation of Foreign Language, however, is incompatible with (PP), according to which it is a necessary condition on the speaker's presupposing that the addressee understands at least some

\footnotetext{
${ }^{28}$ Stalnaker 2002, p. 707 and p. 717. Stalnaker has defended accounts of pragmatic presupposition similar to this one since at least Stalnaker 1974, p. 49, while the general idea underlying the account can already be found in Stalnaker 1970, pp. 38-40. Note also that I am not addressing issues arising from the topic of presupposition accommodation in this paper. See Stalnaker 2002, pp. 708-15 (esp. fn. 14) and von Fintel 2008 for interesting discussion.

${ }^{29}$ Stalnaker 2002, pp. 717, fn. 26.
} 
English that he believes that proposition to be part of the common ground. Thus, if Stalnaker wants to treat Foreign Language as a case of speaker presupposition, then (PP) needs to be amended to cover the case.

Besides Stalnaker's own case there are other, presumably less controversial examples causing trouble for (PP). While Foreign Language isaccording to Stalnaker - a case in which the speaker presupposes $p$ even though he fails to believe that $p$ is common ground, there are also more extreme cases in which the speaker presupposes $p$ even though he knows that $p$ is not and will not become common ground after the utterance. Consider the following dialogue:

\section{Faculty Meeting:}

A: I can't come to the meeting - I have to pick up my sister from the airport.

B: Hang on; I know that you don't have a sister. You're just making up a reason to get around the meeting!

A: That's not true. I have a sister.

B: No, you don't.

A: Yes, I do! I just never told you.

C: Relax! (to A:) Independently of whether you have a sister or not, will you come to the meeting?

A: I'm sorry, but I really won't be able to come. As I said before, I have to pick up my sister from the airport.

According to (PP), A in Faculty Meeting does not pragmatically presuppose that she has a sister when making her last assertion, for she does not believe that proposition to be common ground. After all, A knows from the course of the conversation that B does not accept and will not accept the proposition that A has a sister. However, many theorists - one of them being Stalnaker - take the view that sincere utterances of sentences such as 'I have to pick up my sister from the airport', i.e. sincere utterances of sentences that have semantic presuppositions, are paradigm cases of pragmatic speaker presupposition: on the standard view of presupposition accommodation, any speaker who asserts a sentence that semantically presupposes $p$ ipso facto pragmatically presupposes $p .{ }^{30}$ Thus, as long as we want our account of pragmatic presuppositions to be compatible with the standard accounts of presupposition accommodation, we need to amend (PP) for it to cover cases such as Faculty Meeting. ${ }^{31}$

Fortunately, however, the situation is not as troublesome as it might seem, for the amendment required to cover the above cases is a relatively

\footnotetext{
${ }^{30}$ See Stalnaker 1978, pp. 99-9, Stalnaker 1998, p. 102, Stalnaker 2002, pp. 712-3, and also von Fintel 2008 and Yablo 2006, p. 165.

${ }^{31}$ Faculty Meeting is also a counterexample to the definition of pragmatic presupposition defended in Soames 1982.
} 
slight one. In fact, the key to the problem can be found in Stalnaker's earlier writings on pragmatic presuppositions. Here is a quote from Stalnaker 1974:

I shall say that one actually does make the presuppositions that one seems to make even when one is only pretending to have the beliefs that one normally has when one makes presuppositions. Presupposing is thus not a mental attitude like believing, but is rather a linguistic disposition - a disposition to behave in one's use of language as if one had certain beliefs, or were making certain assumptions. ${ }^{32}$

From this passage we can extract the following definition of pragmatic presuppositions:

(PP*) $x$ pragmatically presupposes $p$ in $C \leftrightarrow x$ is disposed to behave, in her use of language, as if she believed $p$ to be common ground in $C .{ }^{33}$

Even though $\left(\mathrm{PP}^{*}\right)$ appears promising at first sight, it might be objected that the condition it specifies is too weak. Consider the case of truthful Frank, who is always disposed to assert sentences such as (1), i.e. sentences semantically presupposing that he has a sister, simply in virtue of having a sister:

(1) I have to pick up my sister from the airport.

Since asserting sentences such as (1) seems to be behaving, in one's use of language, as if one believed it to be common ground that one has a sister, it seems to follow that Frank constantly pragmatically presupposes that he has a sister. Even worse, generalising from Frank's case, it seems that speakers constantly pragmatically presuppose all sorts of propositions that fail to be part of the common ground. Does this intuitively implausible result endanger $\left(\mathrm{PP}^{*}\right)$ ?

To see why it does not, note that the notion of a pragmatic presupposition is a technical notion that does not necessarily coincide with our intuitions

\footnotetext{
${ }^{32}$ Stalnaker 1974, p. 52; emphasis added. A closely related passage is Stalnaker 1978 , p. 84: "A proposition is presupposed if the speaker is disposed to act as if he assumes or believes that the proposition is true, and as if he assumes or believes that his audience assumes or believes that it is true as well."

${ }^{33}$ Note that a partial disposition of the relevant kind is, strictly speaking, sufficient for pragmatic presupposition. For instance, at the end of Faculty Meeting A is disposed to assert 'I have to pick up my sister from the airport' but she is not disposed to answer 'yes' when asked whether it is common ground that she has a sister. Being disposed to answer 'yes' when asked whether $p$ is common ground, however, is surely required for being fully (i.e. in all respects) disposed to behave, in one's use of language, as if one believed $p$ to be common ground. Thus, a full disposition of the relevant kind is not required for pragmatic presupposition and $\left(\mathrm{PP}^{*}\right)$ is strictly speaking false: it needs to be qualified by inserting 'partially' into its right-hand side. In what follows I leave this qualification aside for stylistic reasons.
} 
about the use of the English word 'presupposition'. Moreover, distinguishing closely between a pragmatic presupposition, which is a behavioural disposition, and the behavioural manifestation of a pragmatic presupposition, the implausibility of $\left(\mathrm{PP}^{*}\right)$ can be explained away: truthful Frank in fact constantly pragmatically presupposes that he has a sister, but he surely does not constantly manifest that pragmatic presupposition.

Leaving aside the above objection to $\left(\mathrm{PP}^{*}\right)$, note that we have finally arrived at an account that positions pragmatic presuppositions within the realm of the voluntary. Since one has direct voluntary control over one's behavioural dispositions, one can, on the basis of ( $\left.\mathrm{PP}^{*}\right)$, consciously decide to presuppose a proposition $p .{ }^{34},{ }^{35}$ Furthermore, note that the notion of a

\footnotetext{
${ }^{34}$ It might be objected here that we have as much voluntary control over our attention as we have over our behavioural dispositions, because we typically can, when asked to attend to a particular object before us, freely decide to attend to it or not: we usually have, it seems, voluntary control over which objects we attend to. In response to this objection it is instructive to distinguish between the perceptual act of attending to physical objects (perception) and the intellectual act of attending to propositions or possibilities (thought). It is surely correct that perceptual attendance is subject to a large degree of voluntary control, but this does not seem to be the case with intellectual attendance, the notion at issue in Lewis's Rule of Attention: in order to decide whether one attends to a certain possibility, one needs to direct one's mind towards that very possibility and thus needs to attend to it. As a consequence, one cannot successfully decide not to attend to a certain possibility: acts of intellectual attendance are not subject to voluntary control in the way in which acts of perceptual attendance are. Moreover, note that when somebody mentions or expresses a possibility in conversation the listener attends to that possibility purely in virtue of cognitively processing and interpreting the speaker's assertions. In interpreting language, one inevitably directs one's mind towards the propositions and possibilities expressed by the speaker.

${ }^{35} \mathrm{~A}$ few remarks on the notion of direct voluntary control are in order. What is direct voluntary control? A state of affairs is under your direct voluntary control iff your mere choosing to perform a certain action is sufficient to bring about that state of affairs. For instance, imagining that you have a red nose is, under normal circumstances, under your direct voluntary control, for as soon as you choose to imagine that you have a red nose, you imagine that you have a red nose. Similarly, your behavioural linguistic dispositions are, under normal circumstances, under your direct voluntary control: as soon as you choose to be disposed to assert sentences such as 'I have to pick up my sister from the airport', you are disposed to assert sentences such as 'I have to pick up my sister from the airport'.

A given state of affairs is, however, under your indirect voluntary control iff it is (a) not under your direct voluntary control, but (b) you can nevertheless bring about that state of affairs by choosing actions that bring it about. For instance, raising your blood pressure is under your indirect voluntary control: by merely choosing to raise your blood pressure, your blood pressure will not be raised. However, since you can choose to exercise in order to raise your blood pressure, you have indirect voluntary control over your blood pressure. Another example of indirect voluntary control is my current belief that there is a banana on my desk. I (presumably) cannot believe that there is a banana on my desk merely by choosing to believe that there is a banana on my desk (I should note that there is no banana on my desk), but I can choose to place a banana on my desk, which would bring about my believing that there is a banana on my desk. For further background on the distinction between direct and indirect voluntary control see Alston 2005, ch. 4.
} 
pragmatic presupposition thus defined stands in a very tight relationship to the notion of taking seriously: those possibilities that are taken seriously or that are treated as the 'live options' in a conversation are precisely those possibilities that are consistent with what is pragmatically presupposed in the corresponding context. In other words, the possibility that $p$ is taken seriously in a conversation iff the participants to that conversation are not disposed to behave, in their use of language, as if they believed $p$ to be common ground: the notions of what is taken seriously in a conversation and of what is pragmatically presupposed in a conversation are interdefinable. ${ }^{36}$ Let us now return to the topic of 'knowledge'-ascriptions. ${ }^{37}$

\section{The View and Some Objections}

Let me briefly recapitulate the view developed thus far. The core of my approach consists in the Lewisian idea that the satisfaction of 'know' is closely tied to the elimination of relevant counter-possibilities by one's evidence. Here is $(\mathrm{L})$ :

(L) $x$ satisfies 'knows $p$ ' in context $C \leftrightarrow x$ 's evidence eliminates every $\neg p$ world, except for those that are properly ignored in $C$.

My view diverges from Lewis's, however, with regard to the definition of the notion of proper ignoring: while Lewis aims to account for the contextsensitivity of 'know' by means of his Rule of Attention:

(RA) If $w$ is attended to by the speakers in $C$, then $w$ is not properly ignored in $C$.

I replaced (RA) with what I have called the 'Rule of Presupposition':

(RP) If $w$ is compatible with the speakers' pragmatic presuppositions in $C$, then $w$ cannot be properly ignored in $C$.

Furthermore, I have given substance to (RP) by explicating the notion of a pragmatic presupposition along Stalnakerian lines:

(PP*) $x$ pragmatically presupposes $p$ in $C \leftrightarrow x$ is disposed to behave, in her use of language, as if she believed $p$ to be common ground in $C$.

\footnotetext{
${ }^{36}$ Of course, what a participant to a conversation takes seriously for herself can differ from what she takes seriously for the purposes of the conversation and thus from what is taken seriously in the conversation. I discuss the significance of this point in Sections 5-6.

${ }^{37}$ Note that $\left(\mathrm{PP}^{*}\right)$ does not define the notion of a pragmatic presupposition in terms of the pretence to believe that $p$ is common ground, a strategy that has been criticised by Gauker (1998) and, building on Gauker's objections, by von Fintel (2008), who seems to reject $\left(\mathrm{PP}^{*}\right)$ on the basis of Gauker's arguments. However, since pretending that one believes $p$ and behaving linguistically as if one believed $p$ are two entirely different notions, Gauker's arguments do not pose a threat to ( $\left.\mathrm{PP}^{*}\right)$.
} 
In what follows, I will call the conjunction of $(\mathrm{L}),(\mathrm{RP}),\left(\mathrm{PP}^{*}\right)$ and the remaining Lewisian rules of proper ignoring, i.e. the Rule of Actuality, Resemblance, Belief, Reliability, Method, and Conservatism, Presuppositional Epistemic Contextualism (PEC).

Before taking a closer look at how PEC resolves sceptical puzzles and accounts for other data contextualists typically cite in support of their theories, we need to clear away a few objections to PEC. To begin with, consider the objection that PEC makes it impossible to assign truth-conditions to sentences of the form ' $x$ knows $p$ ' with respect to contexts in which no conversation takes place, such as the context of the solitary thinker or, for that matter, the soliloquist. The rationale behind this objection is that since the notion of a pragmatic presupposition is defined in terms of what is common ground in a conversation, it is unclear what determines the content of the solitary thinker's thoughts or the soliloquist's utterances. How can we make sense of the idea that the solitary thinker is making pragmatic presuppositions if there are no conversational partners he is conversing with?

The answer to this objection is, I take it, that we ought to conceive of the solitary thinker as being in a covert conversation with himself: thought is a limiting case of communication, one in which the common ground collapses into the set of propositions the thinker accepts, believes himself to accept, etc. A datum indicating that this is the right way to think about thought is that one can think thoughts that have presuppositions, such as the thought that one has to pick up one's sister from the airport or the thought that one regrets having voted for Bush. It is surely not contrived to claim that when thinking such thoughts solitary thinkers pragmatically presuppose that they voted for Bush or that they have a sister, the only difference from ordinary conversation being that the group of participants in the thinker's discourse comprises only the thinker himself. ${ }^{38}$ Obviously, the same considerations apply to cases of soliloquy, the only difference here being that the soliloquist is in an overt, rather than a covert, conversation with himself.

Another interesting fact to be mentioned here is that the problem of determining the content of thoughts of solitary thinkers is not a problem exclusive to the defender of PEC. To the contrary, a strong case can be made that similar issues arise concerning the mental tokenings of many indexical expressions. Consider, for instance, gradable adjectives: whose standards of flatness - if not the solitary thinker's - determine the semantic value of 'flat' as tokened in the solitary thinker's thought? Consider also the demonstratives 'this' and 'that'. According to the standard view, the semantic values of 'this' and 'that' are fixed by the context, by salience relations, accompa-

\footnotetext{
${ }^{38}$ Note also that there presumably are mental correlates to speech acts such as assertion. If Stalnaker's account of assertion is correct, then the solitary thinker must make pragmatic presuppositions, since this is a necessary condition on making assertions on Stalnaker's account.
} 
nying pointing gestures, etc. ${ }^{39}$ Now, what is the role of context when the solitary thinker thinks the singular thought that that table is brown? Which contextual features determine that his singular thought contains (or refers to) the particular table it contains (or refers to) rather than the one right next to it? The problem of assigning semantic values to mental tokenings of indexicals in the solitary thinker's thought is a problem for any semanticist who claims that demonstratives or gradable adjectives are context-sensitive. As a consequence, cases concerning solitary thinkers do not lend themselves to the formulation of an interesting objection to PEC.

According to the second objection I shall discuss, PEC makes it too easy to satisfy 'knows'. Suppose you tell Lazy Johnny that you will either be at home or at work. Assuming that you are at home, can Lazy Johnny, in his context of solitary deliberation, come to 'know' that you are at home merely by presupposing that you are not at work? Can he properly ignore the possibility that you are at work simply in virtue of presupposing that you are not at work? Obviously, the objection generalises: if Lazy Johnny is free to presuppose propositions at random, can he come to 'know', in his context, any proposition $p$ simply by presupposing all propositions $q$ that are incompatible with $p$ ? Clearly, the answer to these questions must be a resounding 'No'. But how is such a negative response substantiated by PEC?

To see why PEC does not entail what we might call 'easy knowledge' we have to bear in mind that $(\mathrm{RP})$ is a prohibitive rather than a permissive rule: (RP) merely claims that worlds that are 'live options' for the speakers in $C$ cannot be properly ignored in $C$, but it does not claim its converse, viz. that worlds that are not 'live options' for the speakers in $C$ can be properly ignored in $C$. Thus, it does not follow from PEC that Lazy Johnny 'knows', in his own context, that you are at home. However, note that (RP) is not the rule that ensures that worlds in which you are at work cannot be properly ignored. If (RP) does not ensure this, which rule does?

At this point two of the other prohibitive Lewisian rules enter the scene, viz. the Rule of Actuality and the Rule of Resemblance. To see how these two rules ensure that Lazy Johnny does not satisfy 'knows' in his own context note that, according to the Rule of Actuality, the subject's actuality may never be properly ignored. Moreover, according to the Rule of Resemblance, no world $w$ can be properly ignored that is close to another world $w^{*}$ that cannot be properly ignored (in virtue of rules other than the Rule of Resemblance).$^{40}$ Now, since, in the imagined case, there is a world relatively close to actuality in which you are not at home but at work and since actuality cannot be properly ignored, the nearby world in which you are at

\footnotetext{
${ }^{39}$ See Kaplan 1989 or Perry 2001.

${ }^{40}$ See Lewis 1996, p. 227. As Lewis emphasises, the bracketed qualification is needed, for otherwise "nothing could be properly ignored; because enough little steps of resemblance can take us from anywhere to anywhere."
} 
work cannot be properly ignored either. In other words, Lazy Johnny can presuppose that you are not at work, but he nevertheless cannot properly ignore nearby worlds in which you are, simply because they are nearby. In the framework of a Lewisian contextualism, the Rule of Actuality and the Rule of Resemblance together function as a safety condition on the satisfaction of 'know'. ${ }^{41}$

Now, if the safety condition inherent to PEC is meant to ensure that subjects do not satisfy 'know' in cases in which they make inadequate presuppositions, one may wonder what PEC says about the epistemic status of beliefs in necessary truths, for concerning beliefs in necessary truths, there are no nearby worlds in which one's belief is false, and the inherent safety condition therefore does not grip. Thus, if one randomly presupposes necessary truths, PEC, as it has been stated above, implausibly entails that one 'knows' those truths.

However, note that the problem concerning necessary truths is a much more general one for Lewisian accounts such as PEC: if $p$ is a necessary truth, then there are not only no nearby $\neg p$-worlds, there are rather no $\neg p$ worlds at all. Thus, no matter what evidence one has, one's evidence always eliminates all $\neg p$-worlds, and one therefore - on the Lewisian approachalways satisfies 'knows $p$ ' in any context $C$ just in virtue of believing $p$. Naturally, such satisfaction of the predicate 'knows $p$ ' by default will strike many epistemologists as unintuitive. As is familiar, however, Lewis is quite attracted to the thought:

What I choose to call "propositions" are individuated coarsely, by necessary equivalence. For instance, there is only one necessary proposition. It holds in every possibility; hence in every possibility left uneliminated by $x$ 's evidence, no matter who $x$ may be and no matter what his evidence may be. So the necessary

\footnotetext{
${ }^{41}$ Note that the conjunction of the Rule of Actuality and the Rule of Resemblance entails that, for all conversational contexts $C$, no world that resembles the subject's actuality is properly ignored in $C$, and not that there is no nearby $\neg p$-world: $\neg p$-worlds can resemble $p$-worlds to a very high degree (as they do, for instance, in Gettier cases). Moreover, see Sosa 2000 and Williamson 2000 for a defence of safety. Even though Sosa dropped the safety requirement in the light of recent counterexamples (see, for instance, Brueckner and Fiocco 2002 and Comesaña 2005), it is worthwhile noting that such a move is only required if one takes safety to figure in a reductive, non-circular analysis or definition of 'knowledge'. If one is not interested in reductive analyses, however, then one ought to conclude that, firstly, the notion of resemblance at issue is not our intuitive notion of resemblance but a distinctively epistemic one and that, secondly, the notion can only be (circularly) defined in terms of knowledge. On this view the relevant concept of resemblance and the concept of knowledge are vague in exactly the same way. They are, to borrow Lewis's phrasing from Counterfactuals, "two vague concepts [that] are vague in a coordinated way: firmly connected to each other, if to nothing else" (Lewis 1973, pp. 92-4). Thus, the concepts of resemblance and 'knowledge' are both simple and insusceptible to analysis. For the view that 'knowledge' cannot be fully analysed see, among others, Williamson 2000 and Schaffer 2005, p. 259.
} 
proposition is known always and everywhere. ${ }^{42}$

Of course, Lewis has a story to tell about why his view appears implausible, and - even though problematic - that story is not entirely hopeless and implausible itself. ${ }^{43}$ Moreover, note that this feature of Lewis's account is generally not perceived to be a knockdown objection to his version of EC: epistemologists have not rejected Lewis's views on the semantics of 'know' simply because they presuppose coarsely individuated propositions and therefore logical omniscience across contexts. However this may be, let me briefly explicate a different approach to the problem that allows us to pair PEC with a more fine-grained conception of propositions.

Another way to resolve the situation is by adding another condition to our account of the satisfaction of 'knows'. The condition I have in mind is the condition that the subject's belief can only count as 'knowledge' in $C$ if it satisfies 'is properly based' in $C{ }^{44}$ Consider a case in which Lou irrationally presupposes Fermat's Last Theorem (FLT) in virtue of believing it on the basis of tealeaves reading. Does Lou 'know', in his context of private deliberation, that FLT is true? Since there are no worlds in which FLT is false, the only condition Lou needs to satisfy in order to 'know' FLT is the condition that his belief is 'properly based' in $C$. However, Lou's belief is not properly based: by assumption, Lou's belief is based on tealeaves reading, which does not qualify as a generally reliable method of belief formation: Lou's belief is accidentally true only.

Adding a proper basing constraint to our account of the satisfaction of 'know' thus resolves the problem of logical omniscience. However, my view still has as a consequence that having one's belief properly based is sufficient for 'knowing' necessary truths. Even though this consequence of PEC may initially seem implausible, I do not think that it is mistaken: regarding necessary truths there simply are no epistemically deficient ways to believe apart from those involving elements of improper causal sustenance. ${ }^{45}$

Here is a third objection that traditional epistemologists are likely to raise against PEC. Coherentists and foundationalists alike will be tempted to ob-

\footnotetext{
${ }^{42}$ Lewis 1996, p. 223; symbolism adjusted.

${ }^{43}$ See Lewis 1986, ch. 1.4 and Stalnaker 1984, Stalnaker 1987 and Stalnaker 1988.

${ }^{44} \mathrm{I}$ address the issue of whether and if so how one's belief that one is not in a sceptical scenario can be properly based in Section 8 .

${ }^{45}$ Consider Lori and her properly based belief that $p$ that, even though properly based, is not 'knowledge'. By disjunction introduction, Lori infers $(p \vee q)$ from $p$, where $q$ is a necessary truth. Lori seems to have a properly based, necessarily true belief, but she intuitively does not know $(p \vee q)$. To defuse such examples I place a constraint on the proper basing relation figuring in my account of the satisfaction of 'know', viz. the constraint that the subject's belief has to be held for the reason that her evidence eliminates those counterpossibilities that cannot be properly ignored in the context of ascription. Thus, Lori's belief that $p$ is, after all, not properly based in the sense relevant for the satisfaction of 'knowledge'. (Note that this notion of proper basing does presumably not coincide with the notion of proper basing entailed by justification).
} 
ject to my view by demanding that it is a necessary condition on a belief's being 'knowledge' in a context $C$ that our presuppositions are themselves 'known' or at least justified in $C$. How can one 'know' $p$ in $C$ if one's presuppositions are not justified? My response to this objection is simple: the requirement under consideration is misguided, but it may easily be conflated with the perfectly adequate requirement that 'knowledge' must be properly based. Surely, 'knowledge' in $C$ has to be properly based in the sense that we cannot come to 'know' $p$ in $C$ by deriving it from propositions we do not 'know' in $C$. However, note that our 'knowledge' does not rest on our presuppositions in that sense: for instance, my belief that I have hands does not rest on my pragmatic presupposition that I am not a brain in a vat in the sense that I believe that I have hands in virtue of having derived it from the proposition that I am not a brain in a vat (and a few other premises). Thus, if we carefully keep apart these different requirements, i.e. the requirement that the premises of one's derivations need to be 'known' or justified in $C$ and the requirement that one's pragmatic presuppositions need to be 'known' or justified in $C$, the objection at issue loses its bite.

A fourth and related objection is that one's presuppositions have to be proper presuppositions: just as Lewis claimed that some alternatives are properly ignored in a context $C$, PEC might be taken to claim that some propositions are properly presupposed in a context $C$. Even though this objection may seem compelling, note that it misconstrues the structure of my view rather severely. To be precise, the objection assumes that I replace Lewis's notion of proper ignoring with the notion of proper pragmatic presupposing, i.e. it assumes that I replace Lewis's (L) with the following principle:

(L*) $x$ satisfies 'knows $p$ ' in context $C \leftrightarrow x$ 's evidence eliminates every $\neg p$-world, except for those that conflict with what is properly pragmatically presupposed in $C$.

In actual fact, however, I do not subscribe to $\left(\mathrm{L}^{*}\right)$ : the main principle underlying PEC remains Lewis's (L), the crucial difference between Lewis's original account and my view being that I replace Lewis's Rule of Attention with my Rule of Presupposition. Thus, I merely amend Lewis's definition of proper ignoring, but I surely do not replace the entire notion of proper ignoring with a more or less dubious notion of proper pragmatic presupposing. Consequently, there is no need for PEC to explicate such a notion.

The fifth and final objection that I would like to address at this point relates to Lewis's empiricist conception of evidence: according to Lewis, our current evidence consists solely in our current sensory experiences and apparent memories. However, if this is all there is to our evidence, then one must, in order to satisfy 'knows', pragmatically presuppose an enormous number of propositions, including many that one has never consciously entertained. But is it plausible that everyone who satisfies 'knows' in quotidian contexts 
pragmatically presupposes these propositions? Does everyone who satisfies 'knows' in quotidian contexts pragmatically presuppose, for instance, that one's current experiences are veridical, that one is not a brain in a vat or that one is not dreaming? The reply to this objection is straightforward: since pragmatic presuppositions are merely behavioural dispositions, presupposing $p$ does not require one to actually entertain the thought that $p$.

Having dealt with the above objections, let us now see how PEC accounts for the familiar data associated with contextualism.

\section{Sceptical Intuitions and Other Data}

How does PEC account for what I have earlier called the Anti-Sceptical Intuition (ASI), i.e. the intuition that speakers often speak truly when asserting 'I know op' ? ${ }^{46}$ The answer to this question is, I take it, fairly obvious: in quotidian contexts speakers are disposed to behave, in their use of language, as if they believed $\neg s h$ to be common ground, i.e. they are disposed to behave, in their use of language, as if they believed that all participants in their discourse accept $\neg s h$, believed that all believe that all accept $\neg s h$, etc. However, if speakers in quotidian contexts are disposed to behave in such a way, then, according to $\left(\mathrm{PP}^{*}\right)$, they pragmatically presuppose $\neg s h$ and thus can properly ignore $s h$-worlds, for neither (RP) nor any other prohibitive rule of proper ignoring marks out $s h$-worlds as epistemically relevant in quotidian contexts. Thus, in quotidian contexts speakers satisfy 'knows op' and usually speak truly when asserting 'I know $o p$ ' for numerous ordinary propositions about the external world. My new approach to EC offers a straightforward explanation of our anti-sceptical intuitions. ${ }^{47}$

Moreover, note that PEC can also account for the data that are usually put forward in support of EC: in DeRose's Bank Case, for instance, the speakers' pragmatic presuppositions are different between the relevant contexts: in the low-standards context the speakers are disposed to behave, in their use of language, as if they believed it to be common ground that the bank has not changed its hours, whereas this is not the case in the corresponding high-standards context. ${ }^{48}$ Similar considerations apply concerning Cohen's Airport Case: the speakers in the low-standards context are disposed to behave, in their use of language, as if they believed it to be common ground that the flight has not been rescheduled at the last minute, whereas the speakers in the corresponding high-standards context are not so

\footnotetext{
${ }^{46}$ In what follows I use 'op' as a propositional variable ranging over ordinary propositions, i.e. proposition that we believe to know in quotidian contexts (that I have hands) and ' $s h$ ' as ranging over sceptical hypotheses (that I'm a brain in a vat).

${ }^{47}$ On my new approach, speakers must, of course, also properly base their belief that $o p$ for them to satisfy 'knows $o p$ ' in quotidian contexts. I take it to be uncontroversial that this further condition is satisfied.

${ }^{48}$ See DeRose 1992 and Stanley 2005, pp. 3-4 for the Bank Case.
} 
disposed. ${ }^{49}$ Now, why do the stakes in the relevant cases influence the speakers' pragmatic presuppositions? Surely, whether one takes a given possibility seriously or whether one considers it a 'live option' in a given situation depends on what is at stake in that situation: if, in a given context $C$, it is especially important that the bank will be open on Saturday, then I will take seriously the possibility that the bank has change its hours recently and I will therefore not behave as if I believed it to be common ground that the bank has not changed its hours recently. In a context in which it does not matter much whether the bank will be open on Saturday, however, I will not take seriously the possibility that the bank has changed its hours recently and will thus behave, in my use of language, as if I believed it to be common ground that the bank has not changed its hours: I will, in the low-stakes context, but not in the high-stakes context, be disposed to assert sentences such as 'Since the bank has been open last Saturday, it will be open this Saturday'. Thus, what is really relevant to the content of 'knowledge'-ascriptions in the relevant cases are the speakers' pragmatic presuppositions rather than which incompatible possibilities has been attended to: we can easily imagine a case in which a speaker attends, for instance, to the possibility that the bank has changed its hours without this making much of a difference to what is presupposed in the context and thus to the truth-values of 'knowledge'-ascriptions in that context. ${ }^{50}$

Before taking a look at how my new account fares with regard to sceptical puzzles let me firstly recapitulate how Lewis aims to resolve such puzzles. As we have seen in Section 1, on Lewis's original account, the Rule of Attention ensures that in contexts in which sceptical arguments are at issue, sceptical possibilities are not properly ignored: since we inevitably attend to sceptical possibilities when discussing or contemplating sceptical arguments, such possibilities have to be eliminated by our evidence for us to satisfy 'knows $o p$ ', this having as a consequence that we cannot satisfy 'knows $o p$ ' in contexts in which sceptical arguments are discussed or contemplated. Thus, according to Lewis, contexts in which sceptical arguments are presented or discussed are - as opposed to quotidian contexts - inevitably sceptical, i.e. they are inevitably contexts in which we cannot satisfy 'knows $o p$ '.

An obvious problem for this view is, of course, that many subjects do not have sceptical intuitions when considering sceptical arguments. Sceptical intuitions come in degrees: when confronted with sceptical arguments, some subjects have no sceptical intuitions whatsoever, others have fairly strong sceptical intuitions and again others are undecided and oscillate between sceptical and non-sceptical intuitions. Moreover, note that subjects have these intuitions independently of whether they participate in a conversation

\footnotetext{
${ }^{49}$ See Cohen 1999, p. 58 for the Airport Case.

${ }^{50}$ Cases in which speaker and subject do not coincide can be treated accordingly. Note that pragmatic presuppositions often vary with the speakers' practical interests.
} 
about sceptical arguments or merely consider such arguments in a context of solitary philosophical reflection. Table 1 illustrates the situation. ${ }^{51}$

Table 1: Distribution of Sceptical Intuitions (Estimate)

\begin{tabular}{ccc}
\hline & $\begin{array}{c}\text { Conversation about } \\
\text { Sceptical Arguments }\end{array}$ & $\begin{array}{c}\text { Solitary Reflection about } \\
\text { Sceptical Arguments }\end{array}$ \\
\hline Sceptical Intuitions & $20 \%$ & $20 \%$ \\
Unsure & $50 \%$ & $50 \%$ \\
Non-sceptical Intuitions & $30 \%$ & $30 \%$ \\
\hline
\end{tabular}

Whether Table 1 gets the numbers entirely right does not matter much here: even though the actual figures surely depart from my estimate, Lewis is committed to the view that a significant proportion of rational and competent speakers are either mistaken (30\% on my estimate) or at least seriously confused ( $50 \%$ on my estimate) about whether they satisfy the predicate 'knows $o p$ ' in contexts in which sceptical arguments are an issue. What is, according to Lewis, the source of this confusion? Lewis has it that speakers are mistaken or confused about the content of 'know' because they are mistaken or confused about what possibilities can be properly ignored in their own contexts. Obviously, Lewis's error-theory remains rather rough and sketchy: why exactly is it that subjects get confused about contexts and contents and why do similar phenonemena not occur with regard to other indexicals? Can PEC offer a more thorough account of the data in Table 1? Let us firstly consider the semantics of 'know' in solitary as opposed to conversational contexts.

\section{Scepticism in Solitary Contexts}

What happens when a solitary thinker is confronted with a sceptical argument? Obviously, sceptical arguments have different psychological effects on different types of subjects. To impose a rough categorisation I shall, in what follows, distinguish between three general types of subjects, viz. between what I shall call unsteady, persistent and indecisive subjects.

Let us firstly consider the group of unsteady subjects. When encountering sceptical arguments, unsteady subjects almost immediately cease to

\footnotetext{
${ }^{51}$ Note that by 'non-sceptical intuitions' I do not mean anti-sceptical intuitions. Somebody who has non-sceptical intuitions believes the negation of (SI), whereas somebody with anti-sceptical intuitions believes (ASI). (See Section 1 for a definition of '(SI)' and '(ASI)').
} 
pragmatically presuppose the proposition that $\neg s h$ : they give up their disposition to behave, in their use of language, as if they believed $\neg s h$ to be common ground. Do unsteady subjects satisfy 'knows op' in their own contexts of solitary thought when reflecting on sceptical arguments? They rather obviously do not: since the unsteady subject does not pragmatically presuppose $\neg s h$ when considering sceptical arguments, he cannot properly ignore $s h$-worlds and therefore does not satisfy 'knows $o p$ ' in her own context. ${ }^{52}$ Thus, PEC has a straightforward explanation for why some subjects $(20 \%$ on my estimate in Table 1) have sceptical intuitions in contexts of solitary reflection on scepticism: they are unsteady subjects and therefore have, in the relevant type of context, adequate intuitions.

Let us move on to the group of persistent subjects. As should be obvious by now, persistent subjects are so-called because they stick to their pragmatic presupposition that $\neg s h$ when confronted with sceptical arguments, i.e. they remain disposed to behave, in their use of language, as if they believed $\neg s h$ to be common ground. Do persistent subjects satisfy 'knows $o p$ ' in their own contexts of solitary thought when reflecting on sceptical arguments? This is the point where persistence pays off: in virtue of pragmatically presupposing $\neg s h$, the persistent subject properly ignores $s h$-worlds and therefore satisfies, in solitary contexts, the predicate 'knows $o p$ '. As a consequence, PEC also has a straightforward explanation of why some subjects (30\% on my estimate in Table 1) have non-sceptical intuitions in contexts of solitary reflection on scepticism: they are persistent subjects and therefore have, in the relevant type of context, adequate intuitions. ${ }^{53}$

The third and final type of subject to be considered here is the indecisive subject, of whom it is unclear whether or not he pragmatically presupposes $\neg s h$ when encountering sceptical arguments: the indecisive subject is, in the relevant situation, simply unable to make up his mind as to whether or not he should behave, in his use of language, as if he believed $\neg s h$ to be common ground. In practice this means that in certain respects the indecisive subject will seem to pragmatically presuppose $\neg s h$ whereas in other respects he will not. ${ }^{54}$ However, if it is unclear whether or not the indecisive subject pragmatically presupposes $\neg s h$ when considering sceptical arguments, then it follows that it is also unclear whether or not $s h$-worlds can be properly ignored in the relevant type of context: the notion of proper ignoring in $C$ is, after all, partially defined in terms of what is pragmatically presupposed in $C$. Moreover, since the satisfaction of 'knows op' in $C$ is partially defined in terms of the notion of proper ignoring in $C$, it also follows that it is unclear whether ' $x$ knows $o p$ ' expresses a truth in contexts in which

\footnotetext{
${ }^{52}$ Remember that $s h$-worlds resist elimination by evidence.

${ }^{53}$ A prototypical example of a persistent subject is, of course, the Moorean. See Section 8 for a discussion of Mooreanism and its relation to PEC.

${ }^{54}$ For instance, the indecisive subject will be disposed to assert both 'Hey, of course, we aren't brains in vats' and 'You're right, for all we know we are brains in vats'.
} 
the indecisive subject solitarily considers sceptical arguments. Consequently, PEC has an explanation of why some subjects (50\% on my estimate in Table 1) oscillate between sceptical and non-sceptical intuitions when considering sceptical arguments in solitary contexts: they are indecisive subjects and their intuitions are, therefore, as adequate as they can be in a situation in which it is unclear whether ' $x$ knows $o p$ ' expresses a truth or not.

Let me sum up the above considerations about the semantics of 'knows' in solitary contexts by means of Table 2, where the dash ('-') indicates that it is unclear whether the relevant sentence expresses, in the relevant context, a truth or a falsehood. ${ }^{55}$

Table 2: Semantics of ' $x$ knows $o p$ ' in Contexts of Solitary Reflection on Sceptical Arguments (or Soliloquy)

\begin{tabular}{cccc}
\hline & $\begin{array}{c}\text { Unsteady } \\
\text { Subject's Context }\end{array}$ & $\begin{array}{c}\text { Indecisive } \\
\text { Subject's Context }\end{array}$ & $\begin{array}{c}\text { Persistent } \\
\text { Subject's Context }\end{array}$ \\
\hline ' $x$ knows $o p '$ & false & - & true \\
' $x$ does not & true & - & false \\
know $o p$ & & & \\
\hline
\end{tabular}

As is obvious from Table 2, PEC does not need an error-theory with regard to contexts of solitary reflection: since, firstly, subjects with sceptical intuitions are unsteady and since, secondly, subjects with non-sceptical intuitions are persistent and since, thirdly, subjects with unclear intuitions are indecisive, all of the relevant subjects have adequate intuitions. Thus, PEC can account for the data in the third column of Table 1 in a considerably more charitable way than Lewis's original EC, and this is surely good news for the defender of PEC.

\section{Scepticism in Conversational Contexts}

Let us now turn to conversational contexts. What happens when sceptical arguments are the topic of conversation among a given group of speakers? Do sentences of the form ' $x$ knows $o p$ ' express truths in such a situation? Depending on the distribution of unsteady, indecisive and persistent subjects among the group at issue, the answer to this question is either 'yes', 'no' or 'cannot know'. Let us consider three primary distributions of the relevant types of subject.

\footnotetext{
${ }^{55}$ If epistemicism is not one's favourite theory of vagueness, one may even claim that the dashes signify truth-value gaps.
} 
Firstly, consider cases in which all participants to the conversation on scepticism are persistent subjects. Clearly, since $\neg s h$ is pragmatically presupposed in such a situation, it follows that the participants to the conversation can properly ignore $\neg s h$ and thus that their utterances of ' $x$ knows $o p$ ' express truths, assuming that none of the other Lewisian rules that (RP) is to be supplemented with prohibits properly ignoring $s h$-worlds and that $x$ 's belief that $o p$ is properly based. ${ }^{56}$ Secondly, consider cases in which all participants to the conversation on sceptical arguments are unsteady subjects. Obviously, since $\neg s h$ is not pragmatically presupposed in such cases, the participants to the conversation express falsities when uttering sentences of the form ' $x$ knows $o p$ ', granting that $s h$-worlds resist elimination by evidence. Finally, consider defective contexts, i.e. contexts in which some speakers presuppose $\neg s h$ while others do not or, alternatively, contexts in which at least one participant to the conversation is indecisive. Since it is unclear whether $\neg$ sh is pragmatically presupposed in such contexts, it follows that it is also unclear whether ' $x$ knows $o p$ ' expresses a truth, again assuming that $s h$-worlds resist elimination by evidence. ${ }^{57}$

Summing up the above considerations, we attain a picture according to which the topic of conversation in $C$ does not directly determine what can be properly ignored in $C$. Rather, the link between the topic of conversation in $C$ and what can be properly ignored in $C$ is mediated by the speakers' pragmatic presuppositions: since the speakers' pragmatic presuppositions may - but by no means have to - change with the topic of conversation, so may - but by no means has to - what can be properly ignored. Consequently, in contexts in which sceptical arguments are discussed, utterances of ' $x$ knows $o p$ ' are either true or false, or it is altogether unclear whether they are true or false. Table 3 illustrates the situation: ${ }^{58}$

Table 3: Semantics of ' $x$ knows op' in Conversational Contexts in which Sceptical Arguments are Considered

\begin{tabular}{cccc}
\hline & $\begin{array}{c}\text { Speakers do not } \\
\text { presuppose } \neg s h\end{array}$ & $\begin{array}{c}\text { Defective } \\
\text { Contexts }\end{array}$ & $\begin{array}{c}\text { Speakers } \\
\text { presuppose } \neg s h\end{array}$ \\
\hline ' $x$ knows $o p '$ & False & - & True \\
$\begin{array}{c}\text { ' } x \text { does not } \\
\text { know } o p\end{array}$ & True & - & False \\
\hline
\end{tabular}

\footnotetext{
${ }^{56}$ See Section 8 for discussion of how one's belief that $\neg$ sh can be properly based.

${ }^{57}$ Recall that, according to PEC, the satisfaction of 'knows' in $C$ is partially defined in terms of what is mutually pragmatically presupposed in $C$.

${ }^{58}$ Again, if epistemicism is not your favourite theory of vagueness, you may take the dashes to denote truth-value gaps.
} 
Let us now return to the data from the second column of Table 1. How can we account for the fact that competent and rational speakers have different intuitions about the sceptical conclusion in conversational contexts? Obviously, subjects' intuitions in conversational contexts cannot be explained analogously to how subjects' intuitions in solitary contexts could be explained: contrary to the earlier case, we now cannot claim that all subjects in sceptical conversational contexts have sceptical intuitions, that all subjects in non-sceptical conversational contexts have non-sceptical intuitions and that all subjects in contexts in which it is unclear whether 'knows $o p$ ' is satisfied have unclear intuitions. That such an explanation cannot work is immediately obvious from the fact that there often are subjects with differing intuitions in one and the same conversational context. Thus, with regard to conversational contexts in which scepticism is considered an error-theory is needed: some competent speakers must have inadequate intuitions about the sceptical conclusion.

\section{Error-Theory: Context of Utterance vs. Context of Thought}

Why are speakers sometimes mistaken about the truth-values of 'knowledge'ascriptions when sceptical arguments are the topic of their conversations? The answer to this question has, I take it, to do with the fact that subjects are, when engaging in a conversation with other subjects, members of two different contexts: firstly, a public context of utterance in which the subject converses with other speakers and, secondly, a private context of thought in which the subject is, as it were, in a conversation with herself. Under normal circumstances these two types of context coincide in the sense that whatever is pragmatically presupposed in one context is also pragmatically presupposed in the other. However, from time to time the two contexts do not match.

Here is a case for illustration. Imagine you are at a dinner party at the Flintstones' house when Barney utters 'What a cute boy!' pointing to Pebbles, the Flintstones' baby girl. Now, you know that Pebbles is a girl, but you have decided to embarrass Barney further by playing along and pretending that Pebbles is in fact a boy. You reply 'Yes, he's sweet, isn't he?' You are, from now on, disposed to behave, in your use of language, as if you believed it to be common ground that the baby is a boy: you pragmatically presuppose that proposition in your context of utterance. However, there is also a clear sense in which you do not pragmatically presuppose that Pebbles is a boy: you do not pragmatically presuppose that proposition in your private context of thought, which is obvious from the fact that you would not use the proposition at issue as a premise in your practical reasoning. Thus, in your conversation with Barney, the proposition that Pebbles is a boy is pragmatically presupposed but it is not so presupposed in your private 
context of thought. ${ }^{59}$

A similar situation may arise concerning sceptical hypotheses. Consider unsteady Karla: whenever Karla considers a sceptical argument, she immediately stops pragmatically presupposing $\neg s h$ in her context of thought, but not necessarily in her context of utterance: imagine Karla attending a seminar on scepticism by G.E. Moore. Since Karla thinks that agreeing with her professor improves her chances to get good grades, she pretends to believe $\neg s h$ to be common ground: in Moore's seminars, Karla is disposed to behave, in her use of language, as if she believed $\neg$ sh to be common ground even though she does not accept $\neg s h$ in her context of thought. Thus, in the utterance context of Moore's seminars, Karla pragmatically presupposes $\neg s h$, but she surely does not pragmatically presuppose that very proposition in her context of thought. As a result, in Moore's seminar, the sentence 'I know $o p$ ' as uttered by Karla expresses a truth while the very same sentence expresses a falsehood as tokened in her mind.

Moreover, since Karla is truly unsteady, she is firmly convinced that she has no epistemic reasons to accept $\neg s h$ and thus believes that the practice she engages in while in Moore's seminar is epistemically unwarranted and faulty: Karla engages in a game of pretence for purely practical reasons. And since Karla considers the game of pretence that she plays irrelevant with regard to the question of whether she 'really knows op'-just as you would consider the game you played with Barney irrelevant with regard to whether Pebbles really is a boy - she does not have the intuition that she in fact satisfies 'knows op' in her context of utterance.

Thus, Karla is fully aware that $\neg s h$ is pragmatically presupposed in her context of utterance, but she is unaware that her and the other speakers' actual linguistic dispositions determine the semantic value of 'know' as uttered by her. Rather, Karla believes mistakenly that the linguistic dispositions she believes the speakers ought to have or the pragmatic presuppositions she believes the speakers ought to make in the context of utterance determine whether one satisfies 'knows $o p$ ' in the context of utterance. Karla accordingly makes the mistake of believing that the content of 'know' in her context of utterance is sensitive to what she believes ought to be pragmatically presupposed in that context rather than to what is in fact so presupposed. ${ }^{60}$

My error-theory generalises: those who are persistent will pragmatically presuppose $\neg s h$ in their private context of thought and will thus have non-

\footnotetext{
${ }^{59}$ Any case of lying or deceit will be a case in which one's pragmatic presuppositions in one's utterance context diverge from one's presuppositions in one's context of thought.

${ }^{60}$ Why don't I simply claim that Karla's pragmatic presuppositions determine the content of 'know' in her mouth and Moore's the content of 'know' in his mouth? If this were the correct approach to the semantics of 'know', then we should expect speakers to be aware that 'know' can express different contents in different mouths. Failing to be aware of this type of context-sensitivity would be a more severe mistake than giving - due to the normativity of 'knowledge'- priority to what one thinks ought to be presupposed over what is actually presupposed.
} 
sceptical intuitions, independently of whether $\neg s h$ is or is not pragmatically presupposed in their context of utterance. Similarly, those who are indecisive will be unclear as to whether they pragmatically presuppose $\neg s h$ in their private context of thought and will therefore oscillate between sceptical and non-sceptical intuitions, independently of whether $\neg s h$ is or is not pragmatically presupposed in their context of utterance. With regard to sceptical puzzles, I take it, speakers are rather suspicious about the presuppositions of others, which gives us an explanation of why speakers tend to have the same intuitions about scepticism in both solitary and in conversational contexts. PEC does not only account for speakers' intuitions in conversational contexts, but also for the symmetry between intuitions in solitary and conversational contexts as depicted in Table 1.

Even though PEC has the mentioned explanatory advantages, many theorists will have methodological worries about the resolution of sceptical puzzles just sketched. To many theorists my error-theory will seem ad hoc and suspicious - mainly because other indexicals do not seem to be in need of similar error-theories: other indexicals, it may be objected, simply do not give rise to comparable confusions between the semantic value an expression takes in the speaker's context of utterance and the semantic value it takes in the speaker's context of thought. ${ }^{61}$ How serious an objection to PEC is this?

In answering this question it is instructive to note that similar phenomena occur with regard to gradable adjectives such as 'flat' or 'tall'. Paralleling the case of 'know' one can surely have the intuition that nothing is really 'flat' even though a contextually salient object satisfies 'flat' in one's context of utterance. Consider a case in which rather high standards of flatness apply, say because you are conducting high precision measurements in a physics laboratory. When your conversational partner points to a special laboratory table suitable for your purposes and asserts 'Let's use that one, it's flat and nobody is using it at the moment' he surely asserts a truth. However, even though the relevant table satisfies 'flat' in your context of utterance you may still have the intuition that nothing is really 'flat', for instance because you believe that there are no surfaces in our empirical world that contain no bumps whatsoever. Thus, the table at issue satisfies 'flat' in your context of conversation, but it does not do so in your context of thought, in which the standard of flatness is so high that no object in the empirical world satisfies it. ${ }^{62}$ Analogously to Karla in her conversation with Moore one may thus

\footnotetext{
${ }^{61}$ See Schiffer 1996 and Rysiew 2001 for this objection. For comprehensive responses to these objections that are compatible with PEC see and Ludlow 2005, DeRose 2006, Blome-Tillmann 2008. These papers also address other linguistic objections to EC that I do not have the space to discuss here, such as the objection that the disquotational schema cannot be applied to ' $x$ knows $p$ ', that 'knows' is not gradable, etc.

${ }^{62}$ Similar cases arise with 'tall': imagine you are a relatively short European visiting Japan. When your Japanese friends say of someone that he is 'tall', you may easily feel
} 
make the mistake of believing that the content of 'flat' in one's context of utterance is sensitive to the standards of flatness that one believes ought to be in place rather than to those that are in fact in place. Gradable adjectives are in need of an error-theory that can be described along similar lines to the one advocated by PEC. ${ }^{63}$

Finally, it might be objected to my error-theory that it simply does not seem plausible that competent speakers tend to confuse their context of utterance with their context of thought. Why is this a natural mistake to make, given that competent speakers usually do not tend to get confused about whether they are having a conversation or are merely thinking to themselves? So why would they confuse their context of conversation with their context of thought? In response to this objection it is important to note that I do not claim that competent speakers confuse their context of utterance with their context of thought or that they get confused about whether they have a conversation or are merely thinking to themselves. Rather PEC claims that competent speakers are sometimes blind towards the fact that 'knows' as uttered in their public context of conversation is sensitive to what is presupposed in that public context of conversation and not to what is presupposed in their private context of thought. Thus, the mistake that is made is a mistake about the semantic properties of the predicate 'knows', a mistake that - as we have just seen - speakers also tend to make with respect to gradable adjectives such as 'flat' and 'tall'. Now, one might, of course, still wonder why exactly competent speakers are sometimes mistaken about the semantic properties of the expressions at issue. Why are they unaware of the fact that 'flat' as tokened in their public context of utterance is sensitive to the standards of flatness in their public context of utterance rather than to the - possibly differing - standards of flatness in their private context of thought? Surely, the exact answer to this question has to be uncovered by the cognitive psychologist. For the philosopher the fact that competent speakers sometimes make the relevant mistakes provides sufficient support for PEC's error-theory.

\section{Closure, Knowing $\neg s h$ and Proper Basing}

One important moral to be drawn from what has been said thus far is that if we want to keep satisfying 'knows $o p$ ' while discussing scepticism, we have to make sure that we are in a context in which $\neg$ sh is mutually pragmatically presupposed. But how can one ensure that $\neg$ sh remains mutually pragmatically presupposed when one is confronted with a speaker who behaves, in his use of language, as if he did not accept $\neg s h$ ?

that they say something true, but still also feel that the person is not tall. See Unger 1975 for the comparison between 'flat' and 'know'.

${ }^{63}$ See Blome-Tillmann 2008 for a more detailed defence of this analogy. 
In many conversations there is a conversational authority or even a group of conversational authorities who have, to some extent, control over the context in the sense that they have the power to make other participants to the conversation presuppose propositions. An example would be Moore from our imagined seminar, who has the conversational authority over Karla. Conversational authorities are, as it were, in a position to set the framework of the conversation. Usually, when there is a dispute as to whether a possibility is a 'live option' in a context $C$, one of the conversational authorities settles the issue, if necessary by putting their foot down.

Consider, for illustration, a case in which a Moorean puts her foot down but the sceptic does not accept his attempts. What happens? There are two possibilities. Firstly, if the rest of the audience is on the Moorean's side, chances are that the sceptic will eventually be ignored by the group and be excluded from the context: the speakers end up in a Moorean context, even though it seems as if one participant to the conversation does not pragmatically presuppose $\neg s h$. In actual fact, however, the sceptic is no longer a participant to the conversation: he has been excluded from the context. ${ }^{64},{ }^{65}$ The second possibility is that the speakers end up in a context in which two conversational authorities of broadly equal standing clash in their attempts

\footnotetext{
${ }^{64} \mathrm{~A}$ more full-blown account of who counts as a participant in a conversation might be demanded here. For instance, one might wonder whether the sceptic is excluded from the conversion if he keeps interjecting 'But we could be brains in vats!' while the other speakers simply look upon him as an unpleasant distraction. Given that the sceptic is not completely ignored in such a case, is he excluded from the conversation? It is important to note at this point that the notion of a conversational participant is vague: it is unclear whether the sceptic is, in the above case, a participant to the conversation or not. Given that the notion is vague, however, it might be objected that PEC is no less occult than other relevant alternatives versions of EC (cp. my complaint in fn. 8, p. 3). Note, however, that this objection is misguided, for the predicate 'knows' is surely vague itself. And given that 'knows' is vague, there is nothing wrong with defining it in terms of another vague concept. In fact, vague concepts are to be defined in terms of other vague concepts, if they are to be defined at all. Thus, the concepts of 'knowledge' and of a conversational participant are, as Lewis might have put it, "two vague concepts [that] are vague in a coordinated way: firmly connected to each other, if to nothing else" (Lewis 1973, pp. 92-4). The objector's demand to remove the vagueness of the notion of a conversational participant is accordingly inappropriate. Now, what does this mean for the case of the sceptic who is, in the mentioned case, considered an unpleasant distraction? Given that it is vague whether the sceptic is a participant to the relevant conversation, it is vague whether $\neg s h$ is pragmatically presupposed in the corresponding conversational context. Thus, it is vague, in the corresponding context, whether the speakers satisfy 'knows $o p$ ' or not. See Section 6 for further discussion of 'knowledge' and vagueness.

${ }^{65}$ Note also that it is the social institution of a conversational authority that ensures that you 'know', when discussing with your son, that he sneaked out last night. Assuming that you have the conversational authority over your son, you can, by putting your foot down and uttering in the right tone 'We both know that I haven't merely dreamt that you sneaked out of your window last night!' force your son to behave, in his use of language, as if he believed it to be common ground that you did not merely dream the relevant episode.
} 
to determine the common ground. If, in such a situation, none of the authorities is sidelined by the rest of the group, the speakers end up in a context in which it is unclear whether $\neg s h$ is presupposed or not: the context is, accordingly, a defective context in which it is unclear whether one satisfies 'knows $o p$ ' ${ }^{66}$ However, the prospect of hard-nosed sceptics turning one's context into a defective context should not bother the anti-sceptic too much: sceptics are easily excluded from one's conversation by simply ignoring them. ${ }^{67}$

Another interesting point to be addressed here concerns PEC and its relation to closure principles. According to contextualised closure principles, one is, in a context $C$, in a position to 'know' $\neg s h$ if one 'knows' op in $C$, assuming that one is, in $C$, in a position to 'know' that op implies $\neg s h$. Here is $\left(\mathrm{CL}_{C}\right)$, where the index ' $C$ ' is a meta-linguistic operator quantifying over contexts to the effect that, for instance, the expression ' $K_{C} x t[p]$ ' expresses that $x$ satisfies 'knows $p$ ' in context $C$ :

$\left.\left(\mathbf{C L}_{C}\right)\left(K_{C} x t[o p] \& \diamond\left(K_{C} x t[o p \rightarrow \neg s h)\right]\right)\right) \rightarrow \diamond\left(K_{C} x t[\neg s h]\right)$.

According to PEC, the two conditions in the antecedent of $\left(\mathrm{CL}_{C}\right)$ are satisfied relative to quotidian contexts. Thus, assuming $\left(\mathrm{CL}_{C}\right)$, PEC entails that, in quotidian contexts, we are in a position to satisfy 'knows $\neg s h$ '. However, being in a position to satisfy 'knows $\neg s h$ ' in quotidian contexts entails being in a position to properly base one's belief that $\neg s h$ in such contexts. But how is such proper basing of one's belief that $\neg$ sh possible?

One reliable method to properly base one's belief $p$ in a context $C$ is, of course, by basing it on a competent deduction from a $q$ one 'knows' in $C$. Applying this idea, we may say that $x$ is in a position to properly base her belief that $\neg s h$ in $C$ by competently deducing it from an $o p$ she 'knows' in $C$. For instance, I can, in a quotidian context in which I 'know' that I have hands, come to 'know' that I am not a brain in a vat by competently deducing that proposition from the proposition that I have hands. This is, of course, the Moorean thought. Now, some epistemologists will object to this move and consider it question begging: proper basing is, they will argue, intuitively absent in the case just mentioned. However, as the existence of Mooreans demonstrates, not everybody shares this intuition. To the contrary, Mooreans are firmly convinced that one's belief that $\neg s h$ is properly based in $C$ and qualifies as 'knowledge' in $C$ if it is based on a competent derivation from one's 'knowledge' that $o p$ in $C$. How can we explain these differing intuitions?

\footnotetext{
${ }^{66}$ Eminent philosophers usually have the conversational authority over their seminars and can thus decide what is mutually pragmatically presupposed by influencing their students into being disposed to behave the desired way. This has the interesting effect that the students of eminent philosophers usually take the same approach towards scepticism as their teachers.

${ }^{67}$ For the objection that this does not amount to an intellectually satisfying response to the sceptic see Section 9.
} 
It will be hardly surprising to the reader that the explanation I favour relies on PEC. On my view, those subjects who consider the Moorean reasoning question begging are what I have previously called 'unsteady subjects', i.e. subjects who stop presupposing $\neg s h$ when confronted with the possibility that $\neg s h$. When these subjects derive, in their context of thought, $\neg$ sh from op, $\neg s h$ is no longer pragmatically presupposed. Consequently, unsteady subjects no longer satisfy 'knows $o p$ ', and therefore have the intuition that Moorean derivations cannot provide a proper basis for one's belief that $\neg s h$ : since their private context of deliberation has changed, such derivations fail, after all, to be derivations from propositions that are 'known' in the relevant contexts. However, for persistent subjects such derivations are competent deductions from propositions that are 'known', which has as a consequence that the persistent subject is, at the time of the derivation, in a position to satisfy 'knows $\neg$ sh'. Thus, as opposed to standard accounts of EC, PEC can account for the datum that the Moorean reasoning seems so attractive to some epistemologists but not to others: it seems attractive to persistent subjects but not to unsteady ones. ${ }^{68}$ Thus, Mooreanism and contextualism no longer have to be conceived of as rival accounts of the same data. On the contrary, Mooreanism can be fruitfully integrated into the general

\footnotetext{
${ }^{68}$ Moreover, indecisive subjects will either oscillate between the intuition that the Moorean reasoning can and the intuition that it cannot count as a proper basis for one's belief that $\neg s h$ or they will be entirely confused and, for instance, have the intuition that they satisfy 'knows $o p$ ' while at the same time having the intuition that the Moorean reasoning is question-begging and that one therefore does not satisfy 'knows $\neg s h$ '.
} 
contextualist framework provided by PEC. ${ }^{69},{ }^{70}$

\section{Further Objections}

Before demonstrating how PEC handles some of the most widely discussed objections to EC in the literature, let us once again consider objections that are likely to be raised against the view developed thus far. On the first objection I have in mind the resolution of sceptical puzzles outlined above does not amount to an intellectually satisfying response to the sceptic. To be more precise, it may be objected to my account that the sceptic does not dispute that, in quotidian contexts, we take many things for granted that she does not take for granted. Rather, the sceptic should, the objection goes, be taken to argue that there are no good epistemic grounds for our everyday presuppositions, and thus that they should be abandoned. And to many theorists that may seem to be the important philosophical task, viz.

\footnotetext{
${ }^{69}$ It is worthwhile distinguishing my position from Ram Neta's (2005) account of the phenomenon of 'easy knowledge'. On Neta's contextualist account, inferences from op to $\neg$ sh generate a context-shift: raising uneliminated counter-possibilities in $C$ makes those counter-possibilities relevant in $C$, such that "by raising the [...] hypothesis [that $\neg s h$ ], we move into a context of appraisal in which we can no longer truthfully affirm, and can truthfully deny, [that we 'know op']" (Neta 2005, p. 203). Thus, Neta believes that we cannot come to satisfy 'knows $\neg s h$ ' in $C$ by competently deducing $\neg s h$ from our 'knowledge' that $o p$ in $C$, because our raising the hypothesis that $\neg s h$ triggers a context shift towards sceptical contexts: we cease to satisfy 'knows $o p$ '. Now, note that this view is quite different from PEC, according to which there are many contexts in which we can come to satisfy 'knows $\neg s h$ ' by competently deducing $\neg s h$ from our 'knowledge' that $o p$ in $C$.

Another interesting account relating to the phenomena discussed here has been presented by Bergmann (2004), who argues that a thinker loses her knowledge that $\neg s h$ as soon as she starts doubting whether sh (p. 719). Bergmann does not, however, explain why doubting whether sh has the mentioned effect on one's knowledge. One possible explanation along the lines of PEC is, of course, that thinkers stop presupposing, in their contexts of thought, $\neg s h$ as soon as they begin doubting whether $s h$ and accordingly stop satisfying 'knows $\neg s h$ ' in those contexts. Thus, Bergmann's account can be supplemented by my account to attain an explanation of the phenomenon Bergmann points to. It ought to be emphasised here, however, that Bergmann is not a contextualist and that he does not distinguish between what I have called context of utterance and context of thought. Thus, Bergmann would certainly deny that one can satisfy 'knows $\neg s h$ ' in one's context of thought while failing to do so in one's context of utterance or vice versa.

${ }^{70}$ It might be objected that Mooreanism cannot be integrated into the framework of PEC because it may plausibly be taken to entail invariantism and thus to be incompatible with PEC. However, the view that Mooreanism entails invariantism is unmotivated. On the standard usage of the term (see, for instance, Pritchard 2007, 2008 and Neta 2003b), a Moorean (or Neo-Moorean) is somebody who believes that sceptical challenges can be legitimately responded to by arguments that are structurally parallel to the argument in Moore's Proof of an External World (1939). Since the position advocated in that paper is neutral with respect to the linguistic thesis that the predicate 'knows' is context-sensitive, Mooreanism is best construed as entailing neither invariantism nor contextualism. However, let me emphasise that PEC is incompatible with invariantist versions of Mooreanism and that such versions of the view cannot be integrated within the framework of PEC.
} 
to explain why the presuppositions in operation in quotidian contexts are epistemically legitimate.

In response to this objection let me emphasise that effectively the same concern has already been dealt with above, viz. in Section $3 .^{71}$ There I explained that PEC is not the view that our 'knowledge' rests on our pragmatic presuppositions in the sense that the relevant beliefs have been formed by derivations from the propositions we pragmatically presuppose. And as long as PEC does not make this rather dubious claim about the relation between our 'knowledge' and our pragmatic presuppositions its defender does not have to argue that we have good epistemic grounds for our everyday pragmatic presuppositions. According to PEC we could, in principle, satisfy 'knows $o p$ ' in everyday contexts without being justified in believing what we pragmatically presuppose in those contexts - if only we were not justified in believing (most of) what we pragmatically presuppose in those contexts in virtue of what we 'know' in those contexts: given that we 'know op' in quotidian contexts, we have, as I have explicated in the previous section, excellent epistemic grounds for our pragmatic presupposition that $\neg s h$ in those contexts: in quotidian contexts, our 'knowledge' that op is a good epistemic reason for believing, and therefore for pragmatically presupposing, $\neg$ sh. Let us thus leave aside the above objection but nevertheless stay, for the moment, with the idea that pragmatic presuppositions are, in some sense, to be justified or epistemically legitimate.

So here is another objection to PEC, viz. the objection that the view emerging when we replace PEC's (RP) with the normative principle (RP*) presents a substantive alternative to $\mathrm{PEC}$ - an alternative that offers a better resolution of sceptical puzzles. Here is $\left(\mathrm{RP}^{*}\right)$ :

$\left(\mathbf{R P}^{*}\right)$ If $w$ is compatible with the speakers' epistemically justified pragmatic presuppositions in $C$, then $w$ cannot be properly ignored in $C$.

At first glance $\left(\mathrm{RP}^{*}\right)$ may in fact appear to be better suited for a resolution of sceptical puzzles, for the defender of ( $\left.\mathrm{RP}^{*}\right)$ can claim that when sceptical arguments are under discussion, the epistemic legitimacy or not of one's pragmatic presuppositions is debated.

However, to see why $\left(\mathrm{RP}^{*}\right)$ does not allow for an explanatorily superior resolution of sceptical puzzles note firstly that the notion of 'epistemic justification' is either itself context-sensitive or not. If it is not context-sensitive, then what explains the potential change of context when sceptical arguments are discussed must, assuming $\left(\mathrm{RP}^{*}\right)$, be the fact that the participants to the relevant conversation have stopped pragmatically presupposing $\neg s h$ and not that they have stopped being justified in presupposing $\neg s h$ : their being justified in presupposing $\neg s h$, by assumption, does not vary with context. ${ }^{72}$

\footnotetext{
${ }^{71}$ See p. 19.

${ }^{72} \mathrm{I}$ here ignore views on which we are never justified in pragmatically presupposing $\neg s h$,
} 
Thus, if the justification component in $\left(\mathrm{RP}^{*}\right)$ is meant to be contextually invariant, then it is explanatorily superfluous with respect to our contextualist resolution of sceptical puzzles and we thus ought to replace (RP*) with the considerably simpler (RP).

If, on the other hand, the justification component in $\left(\mathrm{RP}^{*}\right)$ is meant to be itself context-sensitive, then the defender of ( $\left.\mathrm{RP}^{*}\right)$ owes us an account of its context-sensitivity: pending a detailed and informative account of the context-sensitivity of 'justification', nothing has been gained by replacing $(\mathrm{RP})$ with $\left(\mathrm{RP}^{*}\right)$. To the contrary, by replacing $(\mathrm{RP})$ with $\left(\mathrm{RP}^{*}\right)$ we have lost the simplicity and straightforwardness of (RP) and have transformed the problem of modelling the context-sensitivity of 'knows' into the problem of modelling the context-sensitivity of 'justified'. ${ }^{73}$ Of course, the defender of $\left(\mathrm{RP}^{*}\right)$ might be able to meet the challenges associated with this new project, but - as will become obvious in a moment - it is unclear whether the additional complexity of that new project can be compensated for by a genuine increase in explanatory force.

To see in more detail what I have in mind here remember that the intuitive appeal of $\left(\mathrm{RP}^{*}\right)$ consisted in its allowing us to claim that when sceptical arguments are under discussion, the epistemic legitimacy or not of one's presuppositions is debated. Now, it is important to emphasise at this point that the defender of (RP) can accept this claim too and even employ it in her resolution of sceptical puzzles: sincerely discussing the epistemic legitimacy of one's presupposition that $\neg$ sh may cause one to stop pragmatically presupposing $\neg s h$, i.e. it may cause one to stop behaving, in one's use of language, as if one believed $\neg$ sh to be common ground. As I have pointed out above, in Section 6, the topic of one's conversation may, and often does, influence one's pragmatic presuppositions. Thus, the defender of (RP) can embrace the claim that when sceptical arguments are discussed, the epistemic legitimacy of one's presuppositions is debated, and assign this datum (if it is one) an explanatory role with respect to the mechanisms of contextual shifts in the semantics of 'knows': the idea that was meant to motivate $\left(\mathrm{RP}^{*}\right)$ can easily and fruitfully be integrated into the framework of PEC and it is accordingly unclear whether replacing (RP) with the considerably more complex $\left(\mathrm{RP}^{*}\right)$ would in fact result in an explanatorily superior alternative to PEC. ${ }^{74}$

not even in quotidian contexts. For that view would, in conjunction with $\left(\mathrm{RP}^{*}\right)$ and $(\mathrm{L})$, entail that we never satisfy 'knows $o p$ ' and would thus conflict with vast quantities of data concerning the felicitous and competent usage of 'knows' in English (I assume that those data cannot be accounted for by pragmatic mechanisms, but see Schaffer 2004b).

${ }^{73}$ The same holds if justification is taken to be subject-sensitive, in which case the defender of $\left(\mathrm{RP}^{*}\right)$ owes us an account of which factors in the subject's context raise or lower her own epistemic standards.

${ }^{74}$ Note also that versions of PEC that rely on $\left(\mathrm{RP}^{*}\right)$ are no longer compatible with the recently popular view that 'knowledge' is the explanatorily most basic epistemic notion (see Williamson 2000): (RP*) aims to explicate the semantics of 'knows' in terms of a 
A third objection to PEC and its account of the behaviour of 'knows' in sceptical contexts has it that pragmatic presuppositions are not really strong enough to affect the content of 'know', for we can pragmatically presuppose a claim that we do not take seriously. Suppose, for instance, that several deeply and unshakably committed anti-sceptics convene to discuss Descartes' sceptical arguments. The leader of the discussion says, 'Now, for the purposes of our conversation, let's assume that we might now be dreaming.' Given this, and given PEC, the objection goes, the context of utterance seems to be one in which none of our committed anti-sceptics satisfies 'knows' with respect to ordinary propositions about the external world. But this is a rather counterintuitive result: the anti-sceptics still seem to satisfy, even in their current context, 'knows $o p$ ', and they would certainly take themselves to do so. The defender of PEC, however, seems committed to its being the case that they do not satisfy 'knows $o p$ ' in their current context. Thus, it might be objected to PEC that the relevant pragmatic presuppositions are not strong enough to affect the content of 'knows' in the anti-sceptics' context because they are not taking seriously the claim that they might now be dreaming.

In response to this objection it is important to note that pragmatic presuppositions differ in some crucial respects from mere assumptions. In particular, it is important to note that one can assume a proposition $p$, for the purposes of one's conversation, while at the same time failing to pragmatically presuppose $p$-in fact, while at the same time pragmatically presupposing $\neg p$. To illustrate this possibility consider a case in which the leader of a discussion asserts 'We all know it's false, but let's assume that pigs can fly.' Interestingly, for the audience to fully accommodate this utterance they do not only have to comply with the speaker's request and assume that pigs can fly, they rather also have to accommodate the speaker's claim to the effect that pigs cannot fly, i.e. they have to pragmatically presuppose that proposition. ${ }^{75}$ Thus, once the mentioned utterance is fully accommodated into the context, the speakers will still be disposed to behave, in their use of language, as if they believed it to be common ground that pigs cannot fly, even though they now assume that they can.

Indeed, the fact that an accommodating audience will pragmatically presuppose that pigs cannot fly can be further illustrated by noting that the participants to the conversation will, for instance, be disposed to reply with a rather astonished 'Of course they can't!' when asked whether pigs can really fly, while presumably adding to that claim 'But we're assuming, for the moment, that they can.' Furthermore, note that the accommodating participants in the conversation will still be disposed to utter sentences that

\footnotetext{
different epistemic notion, viz. justification.

${ }^{75}$ Strictly speaking, it is, of course, claimed that everybody knows that pigs cannot fly. Factivity, however, ensures that it is implicitly claimed that pigs cannot fly.
} 
semantically presuppose that pigs cannot fly, i.e. they will be disposed to utter sentences such as 'I'm glad that pigs can't fly' or 'It's rather unsurprising that pigs can't fly, given that they don't have wings.' Thus, if the participants to the conversation in question are accommodating, then they pragmatically presuppose the proposition that pigs cannot fly: they are disposed to behave, in their use of language, as if they believed it to be common ground that pigs cannot fly. However, it is important to emphasise that they nevertheless assume, for the purposes of the conversation, that pigs can fly. For instance, they are nonetheless disposed to reason conditionally on the assumption that pigs can fly, to examine the consequences of the view that pigs can fly, etc. Summing up, assuming $p$ in a conversation neither amounts to nor entails pragmatically presupposing $p$ and is even compatible with pragmatically presupposing $\neg p$.

If assuming and pragmatic presupposing can come apart in this way, however, then it is far from clear whether the anti-sceptics in our original case do in fact fail to pragmatically presuppose that they are not dreaming. In fact, I take it to be fairly obvious that the case of the debating antisceptics parallels the pigs-can-fly case in some crucial respects: for instance, even though the anti-sceptics assume, for the purposes of the conversation, that they might be dreaming, they nevertheless do not take that possibility seriously, they know that none of them takes it seriously, they know that they know that none of them takes it seriously, etc. Thus, even though they assume that they might be dreaming, they are nevertheless in all relevant respects disposed to behave, in their use of language, as if they believed it to be common ground that they are not dreaming. Analogously to the above case they are, for instance, still disposed to answer 'Of course we aren't!' when asked whether they are merely dreaming, and they are also still disposed to assert sentences semantically presupposing that they are not dreaming ('I'm glad I'm not dreaming!'), even though they assume, for the purposes of the conversation, that they might be dreaming.

Summing up, pragmatically presupposing $p$ comes with conversational commitments that are neither satisfied by uttering 'Let's assume that $p$ ' nor by complying with that request. If a conversational authority wants to enforce a pragmatic presupposition in a conversation, then she has to compel her conversational participants to behave, in their use of language, as if they believed $p$ to be common ground, which can usually be done by asserting ' $p$, and there's no more discussion about this topic!', but certainly not by urging one's audience to assume that $p$. As a consequence, the defender of PEC is by no means forced to accept that the deeply and unshakably committed anti-sceptics fail to satisfy 'knows $o p$ ' in the above example, for the proposition that they are not merely dreaming is still mutually pragmatically presupposed in the example's context. Thus, the defender of PEC can-and I think should - agree with what seems the most natural interpretation of the case: the anti-sceptics satisfy 'knows' with respect to ordinary propositions, 
despite their assumption that they might be merely dreaming. ${ }^{76}$

Having dealt with the above objections, let us now see how PEC disarms the most familiar objections to epistemic contextualism in the literature.

\section{Pyrrhonism and Elusiveness}

We have seen above that Lewis's original account entails that contexts in which sceptical arguments are at issue are inevitably contexts in which we do not satisfy 'knows $o p$ '. Now, this entailment of his approach has led Lewis to the view that - as the title of his 1996 paper suggests - knowledge is "elusive" in the sense that it "vanishes" or "disappears" under the examining gaze of the epistemologist. Lewis even goes so far to claim that "epistemology destroys knowledge." 77 Here is a quote:

Do some epistemology. Let your fantasies rip. Find uneliminated possibilities of error everywhere. Now that you are attending to them, just as I told you to, you are no longer ignoring them, properly or otherwise. So you have landed in a context with an enormously rich domain of potential counter-examples to ascriptions of knowledge. In such an extraordinary context, with such a rich domain, it never can happen (well, hardly ever) that an ascription of knowledge is true. Not an ascription of knowledge to yourself (either to your present self or to your earlier self, untainted by epistemology); and not an ascription of knowledge to others. That is how epistemology destroys knowledge. But it does so only temporarily. The pastime of epistemology does not plunge us forevermore into its special context. We can still do a lot of proper ignoring, a lot of knowing, and a lot of true ascribing of knowledge to ourselves and others, the rest of the time. [...] That is how knowledge is elusive. Examine it, and straightway it vanishes." ${ }^{78}$

Obviously, Lewis's metaphor of knowledge vanishing or being destroyed by epistemology is to be taken with a pinch of salt. Surely, Lewis's view does not entail that one's knowledge about the external world ever literally vanishes or ever is destroyed when one begins examining it. Rather, the view only entails

\footnotetext{
${ }^{76}$ We might change the example slightly here and have the authority assert 'Let's all accept, for the purposes of the conversation, that we might be dreaming'. In this amended example the proposition that the participants might be dreaming will be common ground, but it will nevertheless not be pragmatically presupposed: the participants to the conversation are still not disposed to behave, in their use of language, as if they believed that proposition to be common ground - even though they presumably believe it to be common ground. Thus, the same arguments and examples apply to this case as the ones discussed above with respect to the notion of assuming for the purposes of the conversation.

${ }^{77}$ Lewis 1996, p. 222.

${ }^{78}$ Lewis 1996, p. 231.
} 
the metalinguistic thesis that if one is in a context in which one satisfies 'knows $o p$ ', one will cease to do so once one begins doing epistemology, for engaging in epistemology on Lewis's view amounts to drawing attention to sceptical possibilities. Thus, it is the satisfaction of 'knows' rather than knowledge itself that is, on Lewis's approach, elusive. ${ }^{79}$

Does PEC entail Lewisian elusiveness? At this point it should be obvious that it does not: Lewisian elusiveness is a consequence of Lewis's Rule of Attention, which I have rejected in favour of the Rule of Presupposition. Thus, whether a context of epistemological discussion qualifies as a sceptical context depends solely on what the speakers in the epistemological discussion pragmatically presuppose rather than on which possibilities they attend to. Since most epistemologists discuss or reflect on epistemological matters while pragmatically presupposing that they are not brains in vats, it follows that most contexts of epistemological enquiry are non-sceptical. PEC is accordingly not troubled by Lewisian elusiveness: according to PEC, sceptical contexts are considerably rarer and more ephemeral than they are on Lewis's account.

The fact that PEC is not troubled by Lewisian elusiveness is an important advantage to the view. Many epistemologists have objected not only to Lewis's approach but rather to EC in general that it makes too much of a concession to the sceptic in entailing that contexts of epistemological enquiry are inevitably sceptical. ${ }^{80}$ Robert Fogelin, for instance, has argued that contextualism faces "the problem of epistemic self-destruction" 81 and is thus equivalent to Pyrrhonism, the rather unattractive view "that philosophical attempts to defend knowledge inevitably wind up undercutting it." 82 The guiding thought underlying such arguments is, of course, the view that a successful epistemological theory must not only respect (ASI) - as Lewis's account does - but must also entail that one satisfies 'knows op' in contexts of epistemological discussion. Let us call this further constraint on epistemological theories Fogelin's Intuition:

(FI) People often speak truly when they assert 'I know op' in contexts of epistemological enquiry and discussion.

\footnotetext{
${ }^{79}$ Similar considerations hold for DeRose's Rule of Sensitivity (DeRose 1995, p. 37), which ensures that contexts in which the predicate 'knows $\neg s h$ ' is used are sceptical contexts. It should be mentioned here, however, that DeRose hedges his rule, admitting in a footnote that, "given certain features of the conversational situation, the Rule of Sensitivity does not operate", such situations constituting "exceptions to the rule" (DeRose 1995, pp. 40, fn. 36). Surely, DeRose is right to hedge his rule along these lines, but it is worth noting that an explanation of the exceptions such as the one offered by my account is more desirable than a hedged rule of thumb such as the Rule of Sensitivity. For a more thorough discussion of DeRose's account see Blome-Tillmann forthcoming.

${ }^{80}$ See, for instance, Feldman 1999, p. 107ff. and Pritchard 2002 for this view.

${ }^{81}$ Fogelin 2000, p. 56.

${ }^{82}$ Fogelin 2000, p. 44.
} 
Clearly, Lewis's account conflicts with (FI). Note that PEC, however, can take this further hurdle identified by Fogelin: as I have pointed out above, on our new account of the semantics of 'know' it is not the case that epistemological contexts are inevitably sceptical (cp. Table 3): as long as the participants to one's conversation on epistemological matters pragmatically presuppose $\neg s h$ one is on the safe side and satisfies 'knows op'. Thus, PEC respects Fogelin's intuition that, in contexts of epistemological discussion, one often speaks truly when asserting 'I know op'.

Fogelin might not yet be happy and require in addition that a feasible epistemology must entail that one satisfies 'knows op' in every context of epistemological enquiry, even when one is directly challenged by a hardnosed sceptic. Here is Fogelin's Intuition Unrestricted:

(FIU) People always speak truly when they assert 'I know op' in contexts of epistemological enquiry and discussion.

But should we really regard it as a goal of our epistemological theories to defend (FIU)? Should we really adopt the view that an intellectually satisfying response to the sceptic must allow us to always speak truly when asserting 'I know $o p$ ', for only such a response can offer the anti-sceptical intellectual reassurance that some theorists desire? I do not think that we should, since (FIU) conflicts with a datum that we certainly have to account for, viz. what I have called earlier the Sceptical Intuition:

(SI) People sometimes speak truly when they assert 'Nobody knows op' in contexts in which sceptical arguments are discussed.

(FI) and (SI) are compatible, but (FIU) and (SI) are not. To resolve the sceptical puzzle, I thus propose to reject (FIU) in favour of the conjunction of (ASI), (FI) and (SI) and to account for the fact that some theorists find (FIU) plausible by means of my error-theory. ${ }^{83}$ Surely, (SI) makes a concession to the sceptic, but - since sceptical contexts are, according to PEC, by no means as pervasive as they are on Lewis's account - this is surely no significant concession. $^{84}$

\footnotetext{
${ }^{83} \mathrm{PEC}$ can account for the fact that some speakers have Fogelin's Intuition Unrestricted and therefore demand more anti-sceptical reassurance by means of the above error-theory: the relevant speakers are persistent subjects and unaware that 'know' as uttered in a conversation is assigned a semantic value in the relevant context of utterance rather than the persistent subject's context of thought. Thus, the fact that some theorists believe that (FIU) is required for an intellectually satisfying response to the sceptic can be accounted for by PEC: the intuition is mistaken, and the mistake is accounted for by PEC's errortheory (cp. Section 7).

${ }^{84}$ Note also that, according to PEC, our 'knowledge' of sceptical hypotheses is not ineffable or, as Williams 2000, p. 81 puts it, "instatable". On Lewis's approach, we satisfy 'knows $\neg s h$ ' in quotidian contexts, but as soon as we aim to articulate this 'knowledge' we undermine it: we attend to $\neg s h, \neg s h$ is no longer properly ignored and we therefore cease to satisfy 'knows $\neg s h$ '. PEC does not have this rather surprising consequence.
} 
Finally, let me make a few more general remarks on the notion of a resolution of sceptical puzzles. Sceptical arguments are usually considered to give rise to philosophical puzzles or paradoxes because their premises are highly plausible while their conclusions are highly implausible. Consequently, as Cohen, DeRose and other contextualists have emphasised frequently, an intellectually satisfying resolution of the sceptical puzzle does not only have to tell us for each premise and the conclusion of the sceptical argument whether it expresses a truth or a falsehood, but also needs to offer an explanation of why our intuitions about the truth values of at least one of the propositions involved was misguided: what was the mistake we made when we got puzzled by the sceptical argument?

The contextualist's response to the challenge of resolving the sceptical puzzle is to claim that the conclusion of the sceptical argument expresses a falsehood in quotidian contexts and that, as a consequence, the sceptical argument is unsound in such contexts. ${ }^{85}$ Thus, either one of its premises expresses a falsehood in quotidian contexts or it is invalid in such contexts. To get a closer understanding of how precisely context influences the soundness of the sceptical argument we need to formulate the argument metalinguistically. We have already seen that the metalinguistic version of the closure principle, i.e. $\left(\mathrm{CL}_{C}\right)$, is valid according to PEC. However, if this is so, where do we have to locate the mistake in the sceptical argument? Ascending semantically, the standard sceptical argument reads as follows: 86

Metalinguistic Sceptical Argument:

$\begin{array}{llll}\left(\mathrm{i}_{C}\right) & K_{C} x t[o p] \rightarrow \diamond\left(K_{C} x t[\neg s h]\right) . & \text { from }\left(\mathrm{CL}_{C}\right) \\ \left(\mathrm{ii}_{C}\right) & \neg \diamond\left(K_{C} x t[\neg s h]\right) . & - & \mathrm{A} \\ \left(\mathrm{iii}_{C}\right) & \neg K_{C} x t[o p] . & \mathrm{i}_{C}, \mathrm{ii}_{C} & M T\end{array}$

Assuming PEC, there obviously are contexts $C$ in which $\left(\mathrm{ii}_{C}\right)$ is false: there obviously are contexts in which it is possible to satisfy the predicate "knows $\neg s h$ ', viz. quotidian contexts. In quotidian contexts, the defender of PEC maintains, we are in a position to satisfy the predicate 'knows $\neg s h$ ', for in such contexts our evidence eliminates all alternatives to $\neg s h$ that are not properly ignored (all alternatives to $\neg$ sh are, after all, properly ignored in such contexts) and, as we have seen in the previous section, in quotidian contexts we can properly base our belief that $\neg s h$ on a competent derivation from our 'knowledge' that $o p$ - as long as we do not stop pragmatically presupposing $\neg s h$. Thus, in quotidian contexts, all conditions for being in a position to 'know $\neg$ sh' are satisfied.

\footnotetext{
${ }^{85}$ The following is a description of standard contextualist views on sceptical puzzles, as it can be found-more or less explicitly - in all major writings of contextualists. See, for instance, Cohen 1999 or DeRose 1995.

${ }^{86}$ See Blome-Tillmann 2006 for extensive discussion of closure-based arguments for scepticism.
} 
The sceptic's non-metalinguistic version of the above argument is accordingly sound when presented in conversational contexts in which $\neg s h$ is not mutually pragmatically presupposed. However, in contexts in which the speakers presuppose $\neg s h$, the argument is unsound, because premise (ii) expresses a falsehood in such contexts. Moreover, in contexts in which it is unclear whether we pragmatically presuppose $\neg s h$, we are not in a position to know whether the argument is sound or not: it is neither clearly sound, nor clearly unsound. ${ }^{87}$ Thus, when the sceptic asserts in her sceptical context: 'Nobody knows $o p$ ', she may well assert a truth, even though this does not affect the truth-values of our 'knowledge'-ascriptions in quotidian contexts. Consequently, PEC resolves the sceptical puzzle by, firstly, assigning truthvalues to the propositions expressed by the sceptical argument in varying contexts and by, secondly, accounting for competent speakers' sometimes mistaken intuitions about those truth values by means of its error-theory (Section 7).

\section{Irrelevance}

If $\mathrm{EC}$ is a linguistic view as outlined above, i.e. a view about the word 'know' and its content, what is its epistemological relevance? Considering Lewis's attempt to resolve sceptical puzzles, this question may appear somewhat surprising. However, Ernest Sosa thinks that EC, even though true, has only little epistemological relevance, if any at all:

The main thesis of $[\mathrm{EC}]$ has considerable plausibility as a thesis in linguistics or in philosophy of language. In applying it to epistemology, however, it is possible to overreach $[\ldots] .{ }^{88}$

Prominent epistemologists such as Keith Lehrer and Hilary Kornblith join Sosa in his assessment of EC, Kornblith declaring straightforwardly that EC is "largely irrelevant to epistemological concerns." ${ }^{89}$ Irrelevance with regard to epistemological concerns, however, is not the only charge the contextualist faces from Sosa's side. In a more recent paper Sosa even wonders whether "epistemology [can] survive contextualism."90 Epistemology providing jobs for philosophers around the world-jobs which may go lost, if epistemology will not survive any kind of contextualism - there is considerable practical reason for a defender of EC to take a closer look at Sosa's objection.

What, then, is Sosa's objection? Firstly, note that Sosa seems to concede both the truth of EC and that EC explains what I have called the anti-sceptical intuition. Moreover, note that Sosa assumes with Lewis that

\footnotetext{
${ }^{87}$ Again, depending on one's favourite theory of vagueness, premise (ii $C$ ) may even fail to have a determinate truth-value in such contexts.

${ }^{88}$ Sosa 2000 , p. 3 .

${ }^{89}$ See Lehrer 2000 and Kornblith 2000, p. 24.

${ }^{90}$ See Sosa 2005.
} 
philosophical contexts such as the context of his paper are inevitably sceptical contexts: in epistemological contexts, Sosa assumes, one attends to sceptical possibilities, this having as a consequence that contexts of epistemological enquiry are sceptical contexts. This fairly standard assumption then leads Sosa to the criticism that

[from (ASI)] it isn't even clearly inferable that people are ever right when, in ordinary contexts, they claim to know things. This will not follow if only because it will not follow that people ever do claim, in an ordinary context, that they know things, as opposed to making utterances of the form 'I know such and such.' The contextualist line deriving from EC hence doesn't much support, for us philosophers, the claim that people do in ordinary contexts after all know things. Nor does it even much support the claim that speakers are often enough right when they say that people know things. This limits the epistemological interest and relevance of $[\mathrm{EC}]$, however interesting and important it may remain as a thesis in linguistics." 91

We can make more obvious what is going on in this passage by introducing some technical language. Let 'KQ' express the content of 'know' in quotidian contexts and let 'KS' express the content of 'know' in sceptical contexts. Now consider (2), which we derive from (ASI) by disquotation:

(2) People often speak truly when they assert that they know op.

Depending on whether the epistemic standards of our present context are those of quotidian contexts or those of sceptical contexts (2) expresses either (3) or (4):

(3) People often speak truly when they assert that they KQ op.

(4) People often speak truly when they assert that they KS op.

Since Sosa assumes with Lewis that contexts of epistemological enquiry are inevitably sceptical contexts, Sosa thinks that (2), in the context of both his and my paper, expresses the proposition expressed by (4). The alleged problem for EC is now that (4) is clearly false, for it suggests that people in quotidian contexts assert that they KS $p$. However, when people in quotidian contexts use the word 'know', its semantic value is always KQ rather than KS. Thus, Sosa complains that contextualists convey a falsehood, when they assert (2) in a context of epistemological discussion.

The obvious reply to Sosa's objection is, of course, that the contextualist ought to distinguish more carefully between the mention and the use of

\footnotetext{
${ }^{91}$ Sosa 2000, p. 4; Sosa's emphasis.
} 
'know' and thus only assert (ASI) instead of the disquoted (2): Sosa's objection rests on a conflation of the use/mention-distinction. ${ }^{92}$ However, this is not the only way in which Sosa's objection can be understood. Rather, Sosa can also be interpreted as objecting to EC that only claims in which epistemological terminology is used as opposed to mentioned can count as epistemological claims. According to this view, Lewis's EC does not qualify as an epistemological theory, since it is only a view about 'knowledge' rather than about knowledge.

Does the problem pointed to by Sosa arise for the defender of PEC? It does not: assuming PEC, contexts of epistemological enquiry are not inevitably sceptical (cp. Table 3 ). As long as $\neg s h$ is mutually pragmatically presupposed the defenders of PEC can legitimately disquote (ASI), assert (2) and thus make use of epistemic terminology. Indeed, when asserting (2) in a context of epistemological enquiry the defender of PEC may even express exactly the same proposition as she does when asserting (2) in quotidian contexts, provided that she and her conversational partners make the sameor at least relevantly similar - pragmatic presuppositions in both contexts. Thus, the defender of PEC speaks truly when asserting (2) in almost any context of epistemological enquiry, except for those rare and ephemeral ones comprising speakers who are not disposed to behave, in their use of language, as if they believed $\neg s h$ to be common ground. ${ }^{93}$

\section{Assertibility}

Finally, let us consider an objection to Lewis's approach stemming from Williamson 2001. ${ }^{94}$ As Williamson points out, Lewis's account entails that one cannot felicitously assert, in contexts of epistemological enquiry, that people satisfy 'knows $o p$ ' in quotidian contexts. Thus, in the epistemology classroom, Lewis cannot felicitously assert (ASI). To establish this conclusion, Williamson firstly points out that the satisfaction of 'knows' in a context $C$ is the norm of assertion in $C$. Here is a variant of Williamson's Rule of Assertion:

(KRA) If your assertion of $S$ conveys $p$ in $C$, assert $S$ in $C$ only if you satisfy 'knows $p$ ' in $C .^{95}$

Now, Williamson points out that since 'know' is a factive verb, any assertion of the form " $x$ speaks truly when asserting 'I know $o p$ " entails - and thus conveys - op. Consequently, when Lewis asserts (ASI) in the epistemology

\footnotetext{
${ }^{92}$ See Blome-Tillmann 2007 for more details on this line of reasoning.

${ }^{93}$ Again, the persistent subject's intuition that utterances of (2) express truths even in sceptical contexts is accounted for by my error-theory.

${ }^{94}$ See Williamson 2001, pp. 26-7. A variant of Williamson's argument can be found in Wright 2005.

${ }^{95}$ See Williamson 2000, ch. 11 for the original Knowledge Rule of Assertion.
} 
classroom, he conveys op. However, on Lewis's account, Lewis himself does not satisfy 'knows $o p$ ' in the epistemology classroom. Thus, it follows from (KRA) that Lewis cannot felicitously assert (ASI) in contexts of epistemological discussion. Lewis again has to make a significant concession to the sceptic: even though his view respects (ASI), Lewis cannot, in contexts of epistemological discussion, felicitously assert and thus defend (ASI) ${ }^{96}$ This is certainly a disquieting consequence: after all, Lewis's account fails to defend our anti-sceptical intuitions.

However, note again that this unpleasant result does not follow for the defender of PEC. As long as $\neg s h$ is mutually pragmatically presupposed in the epistemology classroom, the defenders of PEC can felicitously assert (ASI), i.e. they can felicitously assert that speakers in quotidian contexts satisfy 'knows op': assuming PEC, epistemology classrooms are not inevitably sceptical contexts (cp. again Table 3 on page 26). Thus, the defender of PEC almost always speaks truly when asserting (ASI) in a context of epistemological enquiry, except for those rare and ephemeral contexts comprising speakers who are not disposed to behave, in their use of language, as if they believed $\neg s h$ to be common ground. ${ }^{97}$

\section{Conclusion}

It is time to take stock and sum up the discussion. In this paper I have proposed an amended version of Lewis's contextualist theory of 'knowledge', one that posits a semantic connection between 'knowledge' on the one hand and what is pragmatically presupposed in the speaker's context on the other. The fact that Stalnaker's notion of a pragmatic presupposition, which has already proven fruitful in numerous other areas of linguistic and philosophical enquiry, can be smoothly put to work in the framework of a contextualist theory of 'knowledge' confirms the theoretical significance of Stalnaker's notion and enhances PEC's theoretical and methodological standing: PEC increases its credibility by bringing to light yet another area of philosophical and linguistic enquiry in which pragmatic presuppositions do interesting explanatory work.

Besides being methodologically appealing, however, PEC is also explanatorily powerful: my new presupposition-based approach to contextualism offers a detailed and informative account of the interaction between context and content, and thus gives a clear and precise meaning to what other contextualists have, more or less nebulously, referred to as a context's "epistemic

\footnotetext{
${ }^{96}$ The strongest claim about the topic of scepticism Lewis is entitled to make in the epistemology classroom is the conditional claim that if $o p$, then people satisfy 'knows $o p$ ' in quotidian contexts.

${ }^{97}$ The persistent subject's intuition that (ASI) expresses a truth even in sceptical contexts is again accounted for by my error-theory.
} 
standards". ${ }^{98}$ Also, we have seen that PEC offers a fruitful account of the data relating to sceptical puzzles, that it reconciles the epistemic contextualist idea with Moorean dogmatism, and, finally, that it avoids familiar objections to EC questioning its philosophical relevance. Surely, more work needs to be done on the project that I have called Presuppositional Epistemic Contextualism. However, I hope to have shown that contextualism, rightly construed, is a resourceful and exciting philosophical view and that we ought not to consider it a degenerating research programme. ${ }^{99}$ To the contrary, epistemic contextualism, I take it, deserves a second chance, for we have only just begun to understand the indexicality of 'knowledge'.

\section{References}

Alston, W. P. (2005). Beyond 'Justification' - Dimensions of Epistemic Evaluation. Ithaca, New York, Cornell UP.

Bergmann, M. (2004). "Epistemic Circularity: Malignant and Benign." Philosophy and Phenomenological Research 69(3): 709-727.

Blome-Tillmann, M. (2006). "A Closer Look at Closure Scepticism." Proceedings of the Aristotelian Society, New Series CVI: 383-392.

Blome-Tillmann, M. (2007). "Contextualism and the Epistemological Enterprise." Proceedings of the Aristotelian Society, New Series.

Blome-Tillmann, M. (2008). "The Indexicality of 'Knowledge'." Philosophical Studies 138(1): 29-53.

Blome-Tillmann, M. (forthcoming). "Contextualism, Safety, and Epistemic Relevance." Philosophical Studies.

Brueckner, A. and M. O. Fiocco (2002). "Williamson's Anti-luminosity Argument." Philosophical Studies 110(3): 285-293.

Cohen, S. (1999). "Contextualism, Skepticism, and the Structure of Reasons." Philosophical Perspectives 13: 57-89.

Comesaña, J. (2005). "Unsafe Knowledge." Synthese 146(2): 395-404.

DeRose, K. (1992). "Contextualism and Knowledge Attributions." Philosophy and Phenomenological Research 52: 913-929.

DeRose, K. (1995). "Solving the Skeptical Problem." The Philosophical Review 104: 1-52.

DeRose, K. (2004). "Single Scoreboard Semantics." Philosophical Studies 119: $1-21$.

DeRose, K. (2006). "Bamboozled by Our Own Words: Semantic Blindness and Some Arguments Against Contextualism." Philosophy and Phenomenological Research 73(2): 316-338.

\footnotetext{
${ }^{98}$ See DeRose 2004, for instance, who makes extensive usage of the Lewisian notion of a "conversational score" without explaining which contextual features determine that conversational score.

${ }^{99}$ Cp. Pritchard 2006.
} 
Feldman, R. (1999). "Contextualism and Skepticism." Philosophical Perspectives 13: 91-114.

Fogelin, R. J. (2000). "Contextualism and Externalism: Trading in One Form of Skepticism for Another." Philosophical Issues 10: 43-57.

Gauker, C. (1998). "What is a Contex of Utterance?" Philosophical Studies 91: $149-172$.

Hawthorne, J. (2004). Knowledge and Lotteries. Oxford, OUP.

Heller, M. (1989). "Relevant Alternatives." Philosophical Studies 55: 23-40.

Heller, M. (1999). "The Proper Role for Contextualism in an Anti-Luck Epistemology." Philosophical Perspectives 13: 115-129.

Kaplan, D. (1989). Demonstratives. Themes from Kaplan. J. Almog, J. Perry and H. Wettstein. Oxford/New York, OUP: 481-563.

Kornblith, H. (2000). "The Contextualist Evasion of Epistemology." Philosophical Issues 10: 24-32.

Kvanvig, J. L. (2007). "Contextualism, Contrastivism, Relevant Alternatives, and Closure." Philosophical Studies 134: 131-140.

Lehrer, K. (2000). "Sensitivity, Indiscernibility and Knowledge." Philosophical Issues 10: 33-37.

Lewis, D. (1973). Counterfactuals. Oxford, Blackwell.

Lewis, D. (1986). On the Plurality of Worlds. Oxford, Blackwell.

Lewis, D. (1996). "Elusive Knowledge." Australasian Journal of Philosophy 74: 649-567; reprinted in: DeRose, K. and Warfield, T.A. (eds.) (1999), Skepticism - A Contemporary Reader; Oxford, OUP: 220239.

Ludlow, P. (2005). Contextualism and the New Linguistic Turn in Epistemology. Contextualism in Philosophy - Knowledge, Meaning and Truth. G. Preyer and G. Peter. Oxford, OUP: 11-50.

Lycan, W. G. (1986). Tacit Belief. Belief - Form, Content, and Function. R. J. Bogdan. Oxford, Clarendon Press: 61-82.

Moore, G. E. (1939). "Proof of an External World." Proceedings of the British Academy 25: 273-300.

Neta, R. (2002). "S knows that p." Noûs 36: 663-681.

Neta, R. (2003a). "Contextualism and the Problem of the External World." Philosophy and Phenomenological Research 66(1): 1-31.

Neta, R. (2003b). "Skepticism, Contextualism, and Semantic Self-Knowledge." Philosophy and Phenomenological Research 67(2): 396-411.

Neta, R. (2005). "A Contextualist Solution to the Problem of Easy Knowledge." Grazer Philosophische Studien 69: 183-206.

Neta, R. (forthcoming). "Undermining the Case for Contrastivism." Social Epistemology.

Perry, J. (2001). Reference and Reflexivity. Stanford, CSLI Publications.

Pritchard, D. (2002). "Recent Work on Radical Skepticism." American Philosophical Quarterly 39: 215-257. 
Pritchard, D. (2006). "Review of Jason Stanley's 'Knowledge and Practical Interests'." Notre Dame Philosophical Reviews: http://ndpr.nd.edu/review.cfm?id=6885.

Pritchard, D. (2007). How to be a Neo-Moorean. Internalims and Externalism in Semantics and Epistemology. S. Goldberg. Oxford, OUP: 68-99.

Pritchard, D. (2008). McDowellian Neo-Mooreanism. New Essays on Disjunctivism. A. Haddock and F. Macpherson. Oxford, OUP: 283-311.

Rieber, S. (1998). "Skepticism and Contrastive Explanation." Noûs 32(2): 189-204.

Rysiew, P. (2001). "The Context-Sensitivity of Knowledge Attributions." Nôus 35(4): 477-514.

Schaffer, J. (2004a). "From Contextualism to Contrastivism." Philosophical Studies 119: 73-103.

Schaffer, J. (2004b). "Skepticism, Contextualism, and Discrimination." Philosophy and Phenomenological Research 69: 138-155.

Schaffer, J. (2005). Contrastive Knowledge. Oxford Studies in Epistemology. J. Hawthorne and T. Szabó Gendler. Oxford, OUP. 1: 235-271.

Schaffer, J. (2007). "Knowing the Answer." Philosophy and Phenomenological Research 75(2): 383-403.

Schiffer, S. (1996). "Contextualist Solutions to Scepticism." Proceedings of the Aristotelian Society 96: 317-333.

Soames, S. (1982). "How Presuppositions are Inherited: A Solution to the Projection Problem " Linguistic Inquiry 13: 483-545.

Sosa, E. (1986). "On Knowledge and Context." The Journal of Philosophy 83(10): $584-585$.

Sosa, E. (2000). "Skepticism and Contextualism." Philosophical Issues 10: $1-18$.

Sosa, E. (2005). Contextualism, epistemic, recent work on. Routledge Encyclopedia of Philosophy. E. Craig. London, Routledge: Retrieved November 09, 2005, from http://reproutledge.com/article/P061.

Stalnaker, R. (1970). "Pragmatics." Synthese 22: 272-289; Reprinted in: Stalnaker (1999), pp. 31-46. Page references are to reprint edition.

Stalnaker, R. (1974). Pragmatic Presuppositions; in: Semantics and Philosophy, M. K. Munitz and P. Unger (eds.); New York, NYU Press:197213; Reprinted in: Stalnaker (1999), pp. 47-62. Page references are to reprint edition.

Stalnaker, R. (1978). "Assertion." Syntax and Semantics 9: 315-332; Reprinted in: Stalnaker (1999), p. 78-95. Page references are to reprint edition.

Stalnaker, R. (1984). Inquiry. Cambridge, Mass., MIT Press.

Stalnaker, R. (1987). "Semantics for Belief." Philosophical Topics 15: 177190; Reprinted in: Stalnaker (1999), pp. 117-29. Page references are to reprint edition. 
Stalnaker, R. (1988). Belief Attribution and Context; in: Contents of Thought. R. Grimm and D. D. Merrill. Tucson, U. of Arizona Press: 156-181; Reprinted in: Stalnaker (1999), pp. 150-66. Page references are to reprint edition.

Stalnaker, R. (1998). "On the Representation of Context." Journal of Logic, Language, and Information 7: 3-19; Reprinted in: Stalnaker (1999), pp. 117-29. Page references are to reprint edition.

Stalnaker, R. (1999). Context and Content. Oxford, OUP.

Stalnaker, R. (2002). "Common Ground." Linguistics and Philosophy 25: 701-721.

Stalnaker, R. (2004). "Comments on "From Contextualism to Contrastivism"." Philosophical Studies 119: 105-117.

Stanley, J. (2005). Knowledge and Practical Interests. Oxford, OUP.

Unger, P. (1975). Ignorance: A Case for Scepticism. Oxford, Clarendon.

Villanueva, E. (2000). "What Has Contextualism to Do with Skepticism?" Philosophical Issues 10: 67-71.

von Fintel, K. (2008). "What is Presupposition Accommodation, Again?" Philosophical Perspectives 22(1): 137-170.

Williams, M. J. (2000). "Is Contextualism Statable?" Philosophical Issues 10: $80-85$.

Williams, M. J. (2001). "Contextualism, Externalism and Epistemic Standards." Philosophical Studies 103: 1-23.

Williamson, T. (2000). Knowledge and Its Limits. Oxford, OUP.

Williamson, T. (2001). "Comments on Michael Williams' Contextualism, Externalism and Epistemic Standards." Philosophical Studies 103: 25-33.

Wright, C. (2005). "Contextualism and Scepticism: Even-handedness, Factivity and Surreptitiously Raising Standards." Philosophical Quarterly 55: 236-262.

Yablo, S. (2006). "Non-Catastrophic Presupposition Failure." Content and Modality. Themes from the Philosophy of Robert Stalnaker. J. Thomson and A. Byrne. Oxford, OUP: 164-190. 